\title{
Mesoporous Carbon of Carbonized Human Urine Waste: A Valuable Heterogeneous Catalyst for Chromene and Xanthene Derivative Synthesis
}

\author{
T. A. J. Siddiqui ${ }^{1}$, Shoyebmohamad F. Shaikh ${ }^{2}{ }^{\mathbb{D}}$, Sushil S. Sangale ${ }^{1}$, Siddheshwar D. Raut ${ }^{1}$, \\ Rajaram S. Mane 1,*, Mohd Ubaidullah ${ }^{2}\left(\mathbb{D}\right.$, Badr M. Thamer $^{2}$, Abdullah M. Al-Enizi 2,*(D), \\ Balaji B. Totawar ${ }^{3}$ and Mohammad Shahzad Samdani ${ }^{2}$ \\ 1 School of Physical Sciences, Swami Ramanand Teerth Marathwada University, \\ Nanded 431606, Maharashtra, India; sj.tabassum@gmail.com (T.A.J.S.); sangale.sushil@gmail.com (S.S.S.); \\ sdraut2003@gmail.com (S.D.R.) \\ 2 College of Science, King Saud University, Riyadh 11451, Saudi Arabia; sshaikh1@ksu.edu.sa (S.F.S.); \\ mtayyab@ksu.edu.sa (M.U.); bthamer@ksu.edu.sa (B.M.T.); mosamdani@ksu.edu.sa (M.S.S.) \\ 3 Smt. G. G. Khadse College, Muktainagar 425306, Maharashtra, India; bb.totawar@gmail.com \\ * Correspondence: rajarammane70@gmail.com (R.S.M.); amenizi@ksu.edu.sa (A.M.A.-E.)
}

Received: 23 October 2020; Accepted: 23 November 2020; Published: 24 November 2020

check for updates

\begin{abstract}
Human urine is universal unused waste material that is regularly disposed of by the human body. We, for the first time, presented an economically beneficial, sustainable, and novel route to synthesize mesoporous human urine carbon (HUC)-containing heteroatoms, i.e., $\mathrm{C}, \mathrm{Na}, \mathrm{Cl}, \mathrm{N}, \mathrm{S}$, and $\mathrm{P}$, using a human urine waste. The as-synthesized HUC were envisaged for their structural elucidation, morphology evolution, crystal structure, functional bonding, and elemental composition analyses through various sophisticated technologies. The HUC catalyst had a moderately crystalline nature due to the graphitic phase of carbon with a particle size of $20-50 \mathrm{~nm}$, which was successfully used to synthesizing chromenes, 1,8-di-oxo-octahydroxanthenes, and benzypyrazolylcoumarin and biscoumarin derivatives through a one-pot multicomponent reaction with $20 \mathrm{mg}$ of catalyst in $\mathrm{EtOH} / \mathrm{H}_{2} \mathrm{O}$ solvent. This eco-friendly and simple method offers numerous advantages such as easy purification, clean reaction, and excellent yield for organic synthesis. The HUC catalyst can be recycled ten times and reused multiple times after activation without affecting catalytic performance.
\end{abstract}

Keywords: human urine carbon; room temperature; metal-free; heterocycles; coumarin and biscoumarin derivatives

\section{Introduction}

Carbonaceous materials are important metal-free heterogeneous catalysts of a broad range of research and industrial applications in the branch of organic chemistry [1,2]. Owing to the cost-competitive, light weight, easily available, eco-friendly, and remarkably stable properties, as well as the sustainability of organic synthesis and renewability associated with carbon catalysts, the development of practical strategies to synthesize carbon-based nanocatalysts for catalytic applications has considerably enhanced the demand for synthesis of this material $[3,4]$. Generally, carbon-based catalysts are being successfully applied in multi-component reactions [5], Michael/Aldol additions [6,7], polymerizations [8], epoxide ring opening reactions [9], oxidation reactions [10], and Friedel crafts reactions [11]. The present scenario requires the organic chemist to systematize the research in such a way that it preserves the environment and to develop procedures that are both environmentally and economically suitable. One major objective is, therefore, to simplify in a modern way traditional procedures with the aim of keeping pollution effects to a minimum, 
together with a reduction in energy and raw material consumption. As far as we know, most of the carbon-based catalysts described are obtained using environmentally-harmful methods, such as the use of concentrated sulfuric acid, fuming nitric acid, hydrogen peroxide, potassium permanganate, potassium chlorate, etc., generating a large amount of acidic water and waste gas [12-14]. In line with this is the continuation of our interest in the synthesis of carbon-based materials from abundantly available biogenic materials [15].

Recently, research on designing and synthesizing a series of polyfunctionalized heterocycles has been a topic of potential interest. Chromenes, xanthenes, benzypyrazolyl coumarin derivatives, and biscoumarin derivatives are important classes of heterocyclic compounds with diverse pharmacological properties. Recently, several chemical approaches have been proposed for carbon-based material synthesis to attain unique properties that arise from their size, shape, and composition [16-20]. Jang et al. reported efficient ionic liquid surface-modified carbon nanotubes utilized for the synthesis of chromene derivatives with excellent (94\%) product yield [21]. Mayorala et al. exhibited calcium oxide (calcium hydroxide)/carbon composites for the synthesis of 2-amino-4H-chromene derivatives under mild and solvent-free reaction conditions [22].

In the present study, we report the first sustainable strategy for the synthesis of a carbon nanocatalyst for catalytic applications exploiting the extraordinary properties of carbon-based materials to catalyze important multicomponent organic reactions to producing a valuable heterocyclic compound with high yield and excellent purity. Herein, we propose a simple and convenient synthetic route of carbon material from healthy human urine, which is unused waste material disposed of by the human body. The key advantages of this newly developed process are that use of $\mathrm{EtOH} / \mathrm{H}_{2} \mathrm{O}$ as an eco-friendly reaction media protocol is relatively inexpensive, non-toxic, metal-free, easy for mass production, does not require column chromatography, has good-to-excellent yields, has high atom economy, etc. Heteroatoms, i.e., $\mathrm{C}, \mathrm{Na}, \mathrm{Cl}, \mathrm{N}, \mathrm{S}$, and $\mathrm{P}$, from human urine waste open the door, via a single precursor, for industrial production of medicinally important heterocyclic compounds using environmentally-friendly and readily-available carbon materials.

\section{Experimental Details}

\subsection{Synthesis of Human Urine Carbon Nanomaterial}

Human urine as a raw organic precursor was collected, from a healthy laboratory member with no prior medical examinations, in plastic bottles (falcon tube) that contained various heteroatoms, including urea, potassium, sodium, chloride, and creatinine as major constituents, and other inorganic compounds as extensive constituents along with $95 \%$ water molecules. The average $\mathrm{pH}$ of the collected urine was 6-8, which upon stirring for several hours at a constant temperature of $\sim 100{ }^{\circ} \mathrm{C}$ resulted in a yellowish deposit. Generally, $500 \mathrm{~mL}$ of urine required approximately $24 \mathrm{~h}$ to produce the yellowish residue. The as-obtained yellowish colored product of urine was then transferred to a ceramic boat and carbonized in a tube furnace at $800^{\circ} \mathrm{C}$ under nitrogen atmosphere to form a heterogeneous carbon structure for the purpose of catalysis in synthetic organic chemistry. After carbonization, a grayish black powder was dispersed in a $0.1 \mathrm{M} \mathrm{HCl}$ solution, ultra-sonicated for $10 \mathrm{~min}$ to remove inorganic rock salt present in the prepared carbon, filtered under reduced pressure, and washed a few times with pure water to obtain the black HUC powder. The inorganic black rock salt HUC powder was dried in an oven at $80^{\circ} \mathrm{C}$ for $12 \mathrm{~h}$. From the 3 to $5 \mathrm{~g}$ of grayish black powder of carbon and salts that $500 \mathrm{~mL}$ of human urine produces, $200-400 \mathrm{mg}$ of mesoporous HUC was finally obtained. Details of surface morphology and structural elucidation were attempted. Our work did not include any experiments on live vertebrates or human subjects. The main goal of the present study was to use waste urine from our human (author) body, which could be used as precursors for the synthesis of mesoporous HUC for heterogeneous catalyst activity. 


\subsection{Synthesis of Chromene Derivatives}

A $50 \mathrm{~mL}$ round-bottom flask was charged with $20 \mathrm{mg}$ of HUC catalyst, $100 \mathrm{mg}$ of dimedone, one equivalent of malononitrile, and one equivalent of aromatic aldehyde in $2 \mathrm{~mL}$ of $\mathrm{EtOH} / \mathrm{H}_{2} \mathrm{O}$ (1:1) polar protic solvent. The reaction mixture was stirred, open to the atmosphere, at room-temperature $\left(27^{\circ} \mathrm{C}\right)$ for a specific time, and the reaction conditions were monitored by thin layer chromatography (TLC) until the synthesis of the final solid product. Finally, the solid product was dissolved in dichloromethane solvent and filtered by a simple filtration method to recover the catalyst. The organic solvent was then removed under reduced pressure. The crude product was washed with hot ethanol solvent to afford pure crystalline product.

\subsection{Synthesis of 1,8-Di-Oxo-Octahydroxanthene Derivatives}

To a mixture of dimedone (100 $\mathrm{mg}$ ), aromatic aldehyde (one equivalent) was added to HUC $(20 \mathrm{mg})$, and $3 \mathrm{~mL}$ of $\mathrm{EtOH} / \mathrm{H}_{2} \mathrm{O}$ and the reaction mixture were stirred at room-temperature for a stipulated time frame. After completion of the reaction, the mixture was dissolved in dichloromethane and filtered by a simple filtration to recover the catalyst. The organic solvent was then removed under reduced pressure. The crude products were purified from hot ethanol to afford the pure crystalline products.

\subsection{Synthesis of Benzyl Pyrazolyl Coumarin Derivatives}

We added $20 \mathrm{mg}$ of HUC as a catalyst to a mixture of phenyl hydrazine $(1 \mathrm{mmol})$, ethyl acetoacetate $(1 \mathrm{mmol})$, aromatic aldehyde $(1 \mathrm{mmol})$, and 4-hydroxycoumarin $(1 \mathrm{mmol})$ in $2 \mathrm{~mL}$ of EtOH$/ \mathrm{H}_{2} \mathrm{O}$ (1:1); the resultant reaction mixture was stirred at $50{ }^{\circ} \mathrm{C}$ for the specified reaction time and monitored by TLC until the formation of solid product. After completion of the reaction, the reaction mixture was dissolved in dichloromethane and filtered by simple filtration to recover the catalyst. The crude products were purified from hot ethanol to afford the pure solid products.

\subsection{Synthesis of Biscoumarin Methane Derivatives}

We added $20 \%$ of HUC as a catalyst to a mixture of aromatic aldehyde $2(1 \mathrm{mmol})$ and 4-hydroxycoumarin $8(2 \mathrm{mmol})$ in $2 \mathrm{~mL}$ of $\mathrm{EtOH} / \mathrm{H}_{2} \mathrm{O}(1: 1)$; the resultant reaction mixture was stirred at $50{ }^{\circ} \mathrm{C}$ for the specified reaction time and monitored by TLC until the formation of solid product. After completion of the reaction, the reaction mixture was dissolved in dichloromethane and filtered by a simple filtration to recover the catalyst. The crude products were purified from hot ethanol to afford the pure crystalline products.

\subsection{Spectral Data of ${ }^{1} H$ NMR and ${ }^{13} C N M R$}

${ }^{1}$ H NMR of 2-amino-4-(4-methoxyphenyl)-7,7-dimethyl-5-oxo-5,6,7,8-tetrahydro-4H-chromene-3carbonitrile (4b)

${ }^{1} \mathrm{H}-\mathrm{NMR}\left(\mathrm{CDCl}_{3}, 400 \mathrm{MHz}\right): \delta \mathrm{H}(\mathrm{ppm})=1.03,(\mathrm{~S}, 3 \mathrm{H}), 1.10,(\mathrm{~S}, 3 \mathrm{H}), 2.17-2.126(\mathrm{q}, 2 \mathrm{H}, J=20 \mathrm{~Hz})$, $2.44(\mathrm{~s}, 2 \mathrm{H}), 3.76(\mathrm{~S}, 3 \mathrm{H}), 4.35(\mathrm{~S}, 1 \mathrm{H}), 4.59(\mathrm{~S}, 2 \mathrm{H}), 6.80-6.84(\mathrm{~m}, 2 \mathrm{H}), 7.13-7.16(\mathrm{~m}, 2 \mathrm{H}) ;{ }^{13} \mathrm{C}$ NMR $\left(\mathrm{CDCl}_{3}, 400 \mathrm{MHz}\right): \delta \mathrm{C}(\mathrm{ppm})=27.68,28.90,32.21,34.75,40.66,50.69,113.97,114.21,118.80,128.63$, $135.49,157.39,158.52,161.29,196.04$.

${ }^{1} \mathrm{H}$ NMR of 2-amino-4-(4-bromophenyl)-7,7-dimethyl-5-oxo-5,6,7,8-tetrahydro-4H-chromene-3carbonitrile (4c)

${ }^{1} \mathbf{H}$ NMR $\left(\mathrm{CDCl}_{3}, 400 \mathrm{MHz}\right): \delta \mathrm{H}(\mathrm{ppm})=1.03(\mathrm{~s}, 3 \mathrm{H}), 1.11(\mathrm{~s}, 1 \mathrm{H}), 2.17-2.27,(\mathrm{q}, 2 \mathrm{H}, J=23.6 \mathrm{~Hz})$, $2.45-2.45(\mathrm{~d}, 2 \mathrm{H}, J=0.4 \mathrm{~Hz}), 4.37(\mathrm{~s}, 1 \mathrm{H}), 4.58(\mathrm{~s}, 1 \mathrm{H}), 7.10-7.13(\mathrm{~m}, 2 \mathrm{H}), 7.39-7.43(\mathrm{~m}, 2 \mathrm{H}) ;{ }^{13} \mathrm{C} \mathrm{NMR}$ $\left(\mathrm{CDCl}_{3}, 400 \mathrm{MHz}\right): \delta \mathrm{C}(\mathrm{ppm})=22.80,24.92,27.64,28.96,29.65,30.89,32.02,34.15,35.19,40.57,50.64$, $113.61,121.19,129.34,131.80,142.26,152.80,157.37,161.68,177.57,195.92$. 
${ }^{1} \mathrm{H}$ NMR of 2-amino-4-(3,4-dichlorophenyl)-7,7-dimethyl-5-oxo-5,6,7,8-tetrahydro-4H-chromene-3carbonitrile (4d)

${ }^{1} \mathbf{H}$ NMR $\left(\mathrm{CDCl}_{3}, 400 \mathrm{MHz}\right): \delta \mathrm{H}(\mathrm{ppm})=1.06(\mathrm{~s}, 3 \mathrm{H}), 1.12(\mathrm{~s}, 3 \mathrm{H}), 2.16-2.27(\mathrm{~d}, 2 \mathrm{H}, J=25.2 \mathrm{~Hz})$, $2.45-2.45(\mathrm{~d}, 2 \mathrm{H}, J=0.8 \mathrm{~Hz}), 4.58(\mathrm{~s}, 2 \mathrm{H}), 4.80(\mathrm{~s}, 1 \mathrm{H}), 7.34-7.34(\mathrm{~d}, 1 \mathrm{H}, J=2.4 \mathrm{~Hz}), 7.34-7.34(\mathrm{~d}, 1 \mathrm{H}$, $J=2 \mathrm{~Hz}), 7.43-7.43(\mathrm{dd}) ;{ }^{13} \mathrm{C}$ NMR $\left(\mathrm{CDCl}_{3}, 400 \mathrm{MHz}\right): \delta \mathrm{C}(\mathrm{ppm})=27.70,28.92,29.71,30.97,32.14$, $33.61,40.61,50.53,61.17,113.05,118.24,127,41,127.48,127.38,130.04,130.14,130.75,131.49,133.49$, 137.16, 138.64, 141.06, 154.65, 157.89, 162.51, 195.83.

${ }^{1} \mathrm{H}$ NMR of 2-amino-7,7-dimethyl-4-(4-nitrophenyl)-5-oxo-5,6,7,8-tetrahydro-4H-chromene-3carbonitrile (4e)

${ }^{1} \mathbf{H}$ NMR $\left(\mathrm{CDCl}_{3}, 400 \mathrm{MHz}\right): \delta \mathrm{H}(\mathrm{ppm})=1.03(\mathrm{~s}, 3 \mathrm{H}), 1.13(\mathrm{~s}, 3 \mathrm{H}), 2.18-2.29(\mathrm{q}, 2 \mathrm{H}, J=28.8 \mathrm{~Hz})$, $2.48-2.48(\mathrm{~d}, 2 \mathrm{H}, J=0.8 \mathrm{~Hz}), 4.52(\mathrm{~s}, 1 \mathrm{H}), 4.67(\mathrm{~s}, 2 \mathrm{H}), 7.40-7.44(\mathrm{~m}, 2 \mathrm{H}), 8.15-8.19(\mathrm{~m}, 2 \mathrm{H}) ;{ }^{13} \mathrm{C}$ NMR $\left(\mathrm{CDCl}_{3}, 400 \mathrm{MHz}\right): \delta \mathrm{C}(\mathrm{ppm})=27.53,28.80,31.53,32.18,35.73,40.61,50.46,112.93,123.95,128.65$, $147.12,150.67,162.34,195.93,206.97$.

${ }^{1}$ H NMR of 2-amino-4-(3,4-dimethoxyphenyl)-7,7-dimethyl-5-oxo-5,6,7,8-tetrahydro-4H-chromene3-carbonitrile (4f)

${ }^{1} \mathbf{H}$ NMR $\left(\mathrm{CDCl}_{3}, 400 \mathrm{MHz}\right): \delta \mathrm{H}(\mathrm{ppm})=1.05(\mathrm{~s}, 3 \mathrm{H}), 1.12(\mathrm{~s}, 3 \mathrm{H}), 2.19-2.28(\mathrm{q}, 2 \mathrm{H}, J=20 \mathrm{~Hz})$, $2.45(\mathrm{~s}, 2 \mathrm{H}), 3.83(\mathrm{~s}, 3 \mathrm{H}), 3.86(\mathrm{~s}, 3 \mathrm{H}), 4.36(\mathrm{~s}, 1 \mathrm{H}), 4.53\left(\mathrm{~s}, 2 \mathrm{H}, 6.73-6.80(\mathrm{~m}, 3 \mathrm{H}) ;{ }^{13} \mathrm{C} \mathrm{NMR}\left(\mathrm{CDCl}_{3}\right.\right.$, $400 \mathrm{MHz}): \delta \mathrm{C}(\mathrm{ppm})=27.51,29.02,32.16,35.10,40.67,50.66,55.85,63.26,111.09,111.25,114.07,118.89$, $119.49,136.08,148.02,148.85,157.54,161.51,196.11$.

${ }^{1}$ H NMR of 2-amino-4-(3-methoxyphenyl)-7,7-dimethyl-5-oxo-5,6,7,8-tetrahydro-4H-chromene-3carbonitrile (4g)

${ }^{1} \mathbf{H}$ NMR $\left(\mathrm{CDCl}_{3}, 400 \mathrm{MHz}\right): \delta \mathrm{H}(\mathrm{ppm})=1.05(\mathrm{~s}, 3 \mathrm{H}), 1.11(\mathrm{~s}, 3 \mathrm{H}), 2.22-2.23(\mathrm{~d}, 2 \mathrm{H}, J=2.4 \mathrm{~Hz})$, 2.44-2.45(t, $2 \mathrm{H} \mathrm{J}=1.6 \mathrm{~Hz}), 3.78(\mathrm{~s}, 3 \mathrm{H}), 4.37(\mathrm{~s}, 1 \mathrm{H}), 4.58(\mathrm{~s}, 2 \mathrm{H}), 6.72-6.77(\mathrm{~m}, 2 \mathrm{H}), 6.81-6.83(\mathrm{~d}, 1 \mathrm{H}$, $J=7.6 \mathrm{~Hz}), 7.18-7.22(\mathrm{t}, 1 \mathrm{H}, J=7.6 \mathrm{~Hz}) ;{ }^{13} \mathrm{C}$ NMR $\left(\mathrm{CDCl}_{3}, 400 \mathrm{MHz}\right): \delta \mathrm{C}(\mathrm{ppm})=27.76,28.88,29.38$, $29.71,31.25,32.21,35.49,38.15,40.67,50.66,55.19,59.52,63.30,112.31,113.51,113.89,118.72,119.94$, $129.59,144.88,157.55,159.73,161.67,195.96$.

${ }^{1}$ H NMR of 2-amino-4-(3,5-dimethoxyphenyl)-7,7-dimethyl-5-oxo-5,6,7,8-tetrahydro-4H-chromene3-carbonitrile (4h)

${ }^{1} \mathbf{H}$ NMR $\left(\mathrm{CDCl}_{3}, 400 \mathrm{MHz}\right): \delta \mathrm{H}(\mathrm{ppm})=1.08(\mathrm{~s}, 3 \mathrm{H}), 1.10(\mathrm{~s}, 3 \mathrm{H}), 2.25(\mathrm{~s}, 2 \mathrm{H}), 2.40-2.50(\mathrm{q}, 2 \mathrm{H}$, $J=20 \mathrm{~Hz}), 3.77(\mathrm{~s}, 6 \mathrm{H}), 4.34(\mathrm{~s}, 1 \mathrm{H}), 4.51(\mathrm{~s}, 2 \mathrm{H}), 6.31-6.32(\mathrm{t}, 1 \mathrm{H}, J=4 \mathrm{~Hz}), 6.38-6.39(\mathrm{~d}, 2 \mathrm{H}, J=4 \mathrm{~Hz})$;

${ }^{13} \mathrm{C}$ NMR $\left(\mathrm{CDCl}_{3}, 400 \mathrm{MHz}\right): \delta \mathrm{C}(\mathrm{ppm})=27.86,28.95,32,21,35.48,40.53,50.66,55.39,98.89,105.83$, $109.89,113.74,118.72,151.81,157.45,160.91,161.71,209.09$.

${ }^{1} \mathrm{H}$ NMR of 2-amino-4-(3-bromophenyl)-7,7-dimethyl-5-oxo-5,6,7,8-tetrahydro-4H-chromene-3carbonitrile (4i)

${ }^{1} \mathbf{H}$ NMR $\left(\mathrm{CDCl}_{3}, 400 \mathrm{MHz}\right): \delta \mathrm{H}(\mathrm{ppm})=1.01(\mathrm{~s}, 3 \mathrm{H}), 1.12(\mathrm{~s}, 3 \mathrm{H}), 2.19-2.52(\mathrm{q}, 2 \mathrm{H}, J=20 \mathrm{~Hz}), 2.41-2.52$ $(\mathrm{m}, 4 \mathrm{H}), 4.37(\mathrm{~s}, 1 \mathrm{H}), 4.64(\mathrm{~s}, 2 \mathrm{H}), 7.15-7.23(\mathrm{~m}, 4 \mathrm{H}) ;{ }^{13} \mathbf{C} \mathbf{~ N M R}\left(\mathrm{CDCl}_{3}, 400 \mathrm{MHz}\right): \delta \mathrm{C}(\mathrm{ppm})=27.73$, $28.83,32.26,35.35,40.66,50.60,62.82,112.02,113.19,118.38,122.72,123.66,128.63,130.16,130.38,130.48$, $131.09,132.56,133.48,137.28,145.46,157.63,158.21,161.84,195.80$.

${ }^{1} \mathrm{H}$ NMR of 2-amino-4-(4-fluorophenyl)-7,7-dimethyl-5-oxo-5,6,7,8-tetrahydro-4H-chromene-3carbonitrile (4j)

${ }^{1} \mathbf{H}$ NMR $\left(\mathrm{CDCl}_{3}, 400 \mathrm{MHz}\right): \delta \mathbf{H}(\mathrm{ppm})=1.03(\mathrm{~S}, 3 \mathrm{H}), 1.11(\mathrm{~S}, 3 \mathrm{H}), 2.18-2.27(\mathrm{q}, 2 \mathrm{H}, J=20 \mathrm{~Hz})$,

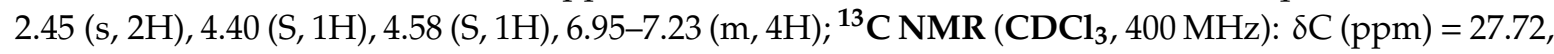
$28.81,32.17,34.91,40.66,50.60,114.00,115.33,115.55,118.53,129.16,129.24,139.00,157.53,160.79$, $161.56,163.07,195.95$.

${ }^{1} \mathrm{H}$ NMR of 2-amino-4-(4-chlorophenyl)-7,7-dimethyl-5-oxo-5,6,7,8-tetrahydro-4H-chromene-3carbonitrile (4k)

${ }^{1} \mathrm{H}$ NMR $\left(\mathrm{CDCl}_{3}, 400 \mathrm{MHz}\right): \delta \mathrm{H}(\mathrm{ppm})=1.03(\mathrm{~S}, 3 \mathrm{H}), 1.11(\mathrm{~S}, 3 \mathrm{H}), 2.17-2.27(\mathrm{q}, 2 \mathrm{H}, J=24 \mathrm{~Hz})$, $2.45(\mathrm{~s}, 2 \mathrm{H}), 4.39(\mathrm{~S}, 1 \mathrm{H}), 4.57(\mathrm{~S}, 2 \mathrm{H}), 7.17(\mathrm{~d}, 2 \mathrm{H}, J=8 \mathrm{~Hz}), 7.23-7.25(\mathrm{~d}, 2 \mathrm{H} J=8 \mathrm{~Hz}) ;{ }^{13} \mathrm{C} \mathrm{NMR}$ $\left(\mathrm{CDCl}_{3}, 400 \mathrm{MHz}\right): \delta \mathrm{C}(\mathrm{ppm})=27.64,28.90,29.71,32.22,35.08,40.66,50.61,113.77,115.76,118.43$, $128.78,129.03,132.93,141.68,157.53,161.62,195.82$. 
${ }^{1} \mathrm{H}$ NMR of 2-amino-4-(4-hydroxyphenyl)-7,7-dimethyl-5-oxo-5,6,7,8-tetrahydro-4H-chromene-3carbonitrile (41)

${ }^{1} \mathbf{H}$ NMR $\left(\mathrm{CDCl}_{3}, 400 \mathrm{MHz}\right): \delta \mathbf{H}(\mathrm{ppm})=1.03(\mathrm{~s}, 3 \mathrm{H}), 1.10(\mathrm{~S} 3 \mathrm{H}), 2.21-2.22(\mathrm{~d}, 2 \mathrm{H}, J=6.8 \mathrm{~Hz})$, $2.44(\mathrm{~S}, 2 \mathrm{H}), 4.3(\mathrm{~S}, 1 \mathrm{H}), 4.48(\mathrm{~S}, 2 \mathrm{H}), 4.75(\mathrm{~S}, 1 \mathrm{H}), 6.726-6.749$ (d, 2H, J = 9.2 Hz), 7.09-7.11 (d, 2H, $J=8.8 \mathrm{~Hz})$.

${ }^{13}$ C NMR of 2-amino-4-(4-hydroxyphenyl)-7,7-dimethyl-5-oxo-5,6,7,8-tetrahydro-4H-chromene-3carbonitrile (41)

${ }^{13} \mathrm{C}$ NMR $\left(\mathrm{CDCl}_{3}, 400 \mathrm{MHz}\right): \delta \mathrm{C}(\mathrm{ppm})=22.69,23.85,27.68,28.88,29.33,29.81,32.21,34.76,38.20$, $115.49,129.02,136.73,137.01,147.65,150.83$.

${ }^{1} \mathrm{H}$ NMR of 2-amino-4-(2-chlorophenyl)-7,7-dimethyl-5-oxo-5,6,7,8-tetrahydro-4H-chromene-3carbonitrile (4m)

${ }^{1} \mathbf{H}$ NMR $\left(\mathrm{CDCl}_{3}, 400 \mathrm{MHz}\right): \delta \mathrm{H}(\mathrm{ppm})=1.07(\mathrm{~S}, 3 \mathrm{H}), 1.11(\mathrm{~S}, 3 \mathrm{H}), 2.16-2.26(\mathrm{~m}, 2 \mathrm{H}), 2.45(\mathrm{~S}, 2 \mathrm{H})$, $4.64(\mathrm{~S}, 2 \mathrm{H}), 4.85(\mathrm{~S}, 1 \mathrm{H}), 7.12-7.33(\mathrm{~m}, 4 \mathrm{H}) ;{ }^{13} \mathrm{C} \mathbf{N M R}\left(\mathrm{CDCl}_{3}, 400 \mathrm{MHz}\right): \delta \mathrm{C}(\mathrm{ppm})=27.73,28.81$, 32.17, 34.91, 40.66, 50.60, 114.00, 115.33, 118.53, 129.16, 129.24, 139.00, 157.53, 160.79, 161.56, 163.07, 195.95.

${ }^{1} \mathrm{H}$ NMR of 3,3,6,6-tetramethyl-9-p-tolyl-3,4,5,6,7,9-hexahydro-1H-xanthene-1,8(2H)-dione (5a)

${ }^{1} \mathbf{H}$ NMR $\left(\mathrm{CDCl}_{3}, 400 \mathrm{MHz}\right): \delta \mathrm{H}(\mathrm{ppm})=0.93(\mathrm{~s}, 6 \mathrm{H}), 1.096(\mathrm{~S}, 6 \mathrm{H}), 2.13-2.17(\mathrm{q}, 4 \mathrm{H}), 2.38-2.49(\mathrm{~S}, 3 \mathrm{H})$, $2.45(\mathrm{~S}, 3 \mathrm{H}), 4.70(\mathrm{~S}, 1 \mathrm{H}), 2.24(\mathrm{~S}, 3 \mathrm{H}), 7.00-7.02(\mathrm{~d}, 1 \mathrm{H}, J=7.6 \mathrm{~Hz}), 7.16-7.18(\mathrm{~d}, 1 \mathrm{H}, J=8 \mathrm{~Hz})$.

${ }^{1} \mathrm{H}$ NMR of 3,3,6,6-tetramethyl-9-(2,3,4-trimethoxyphenyl)-3,4,5,6,7,9-hexahydro-1H-xanthene1,8(2H)-dione (5b)

${ }^{1} \mathbf{H}$ NMR $\left(\mathrm{CDCl}_{3}, 400 \mathrm{MHz}\right): \delta \mathbf{H}(\mathrm{ppm})=1.02(\mathrm{~s}, 6 \mathrm{H}), 1.09(\mathrm{~S}, 6 \mathrm{H}), 2.12-2.24(\mathrm{q}, 4 \mathrm{H}), 2.43(\mathrm{~S}, 1 \mathrm{H})$, $4.81(\mathrm{~S}, 1 \mathrm{H}), 6.53-6.55(\mathrm{~d}, 1 \mathrm{H}, J=8.8 \mathrm{~Hz}), 6.99-7.01\left(\mathrm{~d},{ }^{1} \mathrm{H}, J=28.4 \mathrm{~Hz}\right)$.

${ }^{1} \mathrm{H}$ NMR of 3,3,6,6-tetramethyl-9-(4-nitrophenyl)-3,4,5,6,7,9-hexahydro-1H-xanthene-1,8(2H)-dione (5c) ${ }^{1} \mathbf{H}$ NMR $\left(\mathrm{CDCl}_{3}, 400 \mathrm{MHz}\right): \delta \mathrm{H}(\mathrm{ppm})=0.99(\mathrm{~s}, 6 \mathrm{H}), 1.12(\mathrm{~S}, 6 \mathrm{H}), 2.14-2.27(\mathrm{q}, 4 \mathrm{H}, J=36 \mathrm{~Hz}), 2.49-2.49$ $(\mathrm{d}, 4 \mathrm{H}, J=0.8 \mathrm{~Hz}), 4.82(\mathrm{~s}, 1 \mathrm{H}), 7.46-7.48(\mathrm{dd}, 2 \mathrm{H}, J=6.8 \mathrm{~Hz}), 8.08-8.11(\mathrm{dd}, 2 \mathrm{H}, J=6.8 \mathrm{~Hz})$.

${ }^{1} \mathrm{H}$ NMR of 9-(2-chlorophenyl)-3,3,6,6-tetramethyl-3,4,5,6,7,9-hexahydro-1H-xanthene-1,8(2H)-dione (5d)

${ }^{1} \mathbf{H}$ NMR $\left(\mathrm{CDCl}_{3}, 400 \mathrm{MHz}\right): \delta \mathbf{H}(\mathrm{ppm})=1.01(\mathrm{~s}, 6 \mathrm{H}), 1.10(\mathrm{~S}, 6 \mathrm{H}), 2.13-2.45(\mathrm{q}, 4 \mathrm{H}, J=28.4 \mathrm{~Hz})$, $2.40-2.44(\mathrm{~d}, 4 \mathrm{H}, J=18 \mathrm{~Hz}), 4.99(\mathrm{~s}, 1 \mathrm{H}), 7.04-7.06(\mathrm{t}, 1 \mathrm{H}, J=1.2 \mathrm{~Hz}), 7.08-7.14(\mathrm{t}, 1 \mathrm{H}, J=1.2 \mathrm{~Hz})$, $7.16-7.18(\mathrm{~d}, 1 \mathrm{H}, J=7.2), 7.42-7.44(\mathrm{~d}, 1 \mathrm{H}, \mathrm{J}=7.6 \mathrm{~Hz})$.

${ }^{1} \mathrm{H}$ NMR of 9-(4-bromophenyl)-3,3,6,6-tetramethyl-3,4,5,6,7,9-hexahydro-1H-xanthene-1,8(2H)dione (5e)

${ }^{1} \mathrm{H}$ NMR $\left(\mathrm{CDCl}_{3}, 400 \mathrm{MHz}\right): \delta \mathrm{H}(\mathrm{ppm})=0.99(\mathrm{~s}, 6 \mathrm{H}), 1.09(\mathrm{~S}, 6 \mathrm{H}), 2.16-2.26(\mathrm{q}, 4 \mathrm{H}, J=24.8 \mathrm{~Hz})$, $2.45(\mathrm{~s}, 4 \mathrm{H}), 4.66(\mathrm{~s}, 1 \mathrm{H}), 6.55-6.60(\mathrm{q}, 2 \mathrm{H}, J=13.6 \mathrm{~Hz}), 7.06-7.11(\mathrm{~d}, 2 \mathrm{H}, J=10.4 \mathrm{~Hz})$.

${ }^{1} \mathrm{H}$ NMR of (E)-3,3,6,6-tetramethyl-9-(2-nitrostyryl)-3,4,5,6,7,9-hexahydro-1H-xanthene-1,8(2H)dione (5f)

${ }^{1} \mathbf{H}$ NMR $\left(\mathrm{CDCl}_{3}, 400 \mathrm{MHz}\right): \delta \mathbf{H}(\mathrm{ppm})=1.12(\mathrm{~s}, 12 \mathrm{H}), 2.27-2.37(\mathrm{q}, 4 \mathrm{H}, J=20 \mathrm{~Hz}), 2.40-2.52(\mathrm{q}, 4 \mathrm{H}$, $J=28.8 \mathrm{~Hz}), 4.38(\mathrm{~s}, 1 \mathrm{H}), 6.65-6.65(\mathrm{~d}, 2 \mathrm{H}, J=0.4 \mathrm{~Hz}), 7.29-7.33(\mathrm{t}, 1 \mathrm{H}, J=7.2 \mathrm{~Hz}), 7.47-7.51(\mathrm{t}, 1 \mathrm{H}$, $J=7.6 \mathrm{~Hz}), 7.54-7.56(\mathrm{~d}, 1 \mathrm{H}, J=8 \mathrm{~Hz}), 7.85-7.87(\mathrm{~d}, 1 \mathrm{H}, J=8 \mathrm{~Hz})$.

${ }^{1} \mathrm{H}$ NMR of 9-(2,4-dichlorophenyl)-3,3,6,6-tetramethyl-3,4,5,6,7,9-hexahydro-1H-xanthene-1,8(2H)dione $(5 \mathrm{~g})$

${ }^{1} \mathrm{H}$ NMR $\left(\mathrm{CDCl}_{3}, 400 \mathrm{MHz}\right): \delta \mathrm{H}(\mathrm{ppm})=1.00(\mathrm{~s}, 6 \mathrm{H}), 1.11(\mathrm{~S}, 6 \mathrm{H}), 2.16-2.27(\mathrm{q}, 4 \mathrm{H}, J=24.8 \mathrm{~Hz})$, $2.47(\mathrm{~s}, 4 \mathrm{H}), 4.69(\mathrm{~s}, 1 \mathrm{H}), 7.18-7.32(\mathrm{~m}, 3 \mathrm{H})$.

${ }^{1} \mathrm{H}$ NMR of 3,3,6,6-tetramethyl-9-(3,4,5-trimethoxyphenyl)-3,4,5,6,7,9-hexahydro-1H-xanthene-1,8(2H)dione (5h)

${ }^{1} \mathbf{H}$ NMR $\left(\mathrm{CDCl}_{3}, 400 \mathrm{MHz}\right): \delta \mathrm{H}(\mathrm{ppm})=1.03(\mathrm{~s}, 6 \mathrm{H}), 1.11(\mathrm{~S}, 6 \mathrm{H}), 2.19-2.28(\mathrm{q}, 4 \mathrm{H}, J=19.6 \mathrm{~Hz})$, $2.46-2.47(\mathrm{~d}, 4 \mathrm{H}, J=2.8 \mathrm{~Hz}), 3.77(\mathrm{~s}, 3 \mathrm{H}), 3.81(\mathrm{~s}, 6 \mathrm{H}), 4.71(\mathrm{~s}, 1 \mathrm{H}), 6.51(\mathrm{~S}, 2 \mathrm{H})$.

${ }^{1} \mathrm{H}$ NMR of 9-(4-chlorophenyl)-3,3,6,6-tetramethyl-3,4,5,6,7,9-hexahydro-1H-xanthene-1,8(2H)dione (5i) 


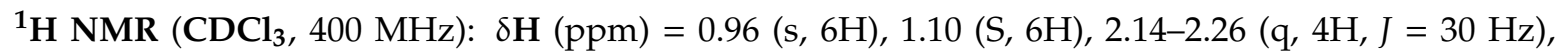
$2.46(\mathrm{~s}, 4 \mathrm{H}), 4.70(\mathrm{~s}, 1 \mathrm{H}), 7.17-7.26(\mathrm{~m}, 4 \mathrm{H})$.

${ }^{1} \mathrm{H}$ NMR of 9-(3,4-dimethoxyphenyl)-3,3,6,6-tetramethyl-3,4,5,6,7,9-hexahydro-1H-xanthene-1,8(2H)dione (5j)

${ }^{1} \mathrm{H}$ NMR $\left(\mathrm{CDCl}_{3}, 400 \mathrm{MHz}\right): \delta \mathrm{H}(\mathrm{ppm})=1.00(\mathrm{~s}, 6 \mathrm{H}), 1.10(\mathrm{~S} 6 \mathrm{H}), 2.16-2.26(\mathrm{q}, 4 \mathrm{H}), 2.46(\mathrm{~S}, 4 \mathrm{H})$, $3.79(\mathrm{~S}, 3 \mathrm{H}), 3.85(\mathrm{~S}, 3 \mathrm{H}), 4.70(\mathrm{~S}, 1 \mathrm{H}), 6.70-6.90(\mathrm{~m}, 3 \mathrm{H})$.

${ }^{1} \mathrm{H}$ NMRof4-((4-hydroxy-2-oxo-2H-chromen-3-yl) (4-nitrophenyl) methyl)-5-methyl-2-phenyl-1Hpyrazol-3 (2H)-one (9a)

${ }^{1} \mathbf{H}$ NMR $\left(\mathrm{CDCl}_{3}, 400 \mathrm{MHz}\right): \delta \mathrm{H}(\mathrm{ppm})=2.44(\mathrm{~s}, 3 \mathrm{H}), 3.66-3.72(\mathrm{q}, 1 \mathrm{H}), 5.84(\mathrm{~s}, 1 \mathrm{H}), 7.11-7.13(\mathrm{~d}, 1 \mathrm{H}$, $J=8 \mathrm{~Hz}), 7.18-7.21(\mathrm{t}, 1 \mathrm{H}, J=8 \mathrm{~Hz}), 7.32-7.39(\mathrm{~m}, 4 \mathrm{H}), 7.49-7.53(\mathrm{~m}, 1 \mathrm{H}), 7.60-7.62(\mathrm{~d}, 1 \mathrm{H}, J=8 \mathrm{~Hz})$, $7.91-7.93(\mathrm{~m}, 1 \mathrm{H}), 8.06-8.08(\mathrm{~d}, 2 \mathrm{H}, J=8 \mathrm{~Hz})$.

${ }^{13} \mathrm{C}$ NMR of 4-((4-hydroxy-2-oxo-2H-chromen-3-yl) (4-nitrophenyl) methyl)-5-methyl-2-phenyl1H-pyrazol-3(2H)-one (9a)

$\left.{ }^{13} \mathrm{C} \mathrm{NMR} \mathrm{CDCl}_{3}, 400 \mathrm{MHz}\right): \delta \mathrm{H}(\mathrm{ppm})=18.31,58.48,106.13,106.76,116.00,118.24,120.71,123.63$, $124.32,124.68,127.13,128.02,129.39,132.37,135.02,146.88,147.28,152.33,162.75,165.78,166.33$.

${ }^{1}$ H NMR of 3,3'-p-tolyl methylene) bis(4-hydroxy-2H-chromen-2-one)

${ }^{1} \mathbf{H}$ NMR $\left(\mathrm{CDCl}_{3}, 400 \mathrm{MHz}\right): \delta \mathrm{H}(\mathrm{ppm})=6.27(\mathrm{~s}, 1 \mathrm{H}), 6.76-6.79(\mathrm{~d}, 2 \mathrm{H}, J=12 \mathrm{~Hz}), 7.03-7.05(\mathrm{~d}, 2 \mathrm{H}$, $J=8 \mathrm{~Hz}), 7.28-7.35(\mathrm{~m}, 4 \mathrm{H}), 7.55-7.59(\mathrm{t}, 2 \mathrm{H}, J=8 \mathrm{~Hz}), 7.87-7.89(\mathrm{~d}, 2 \mathrm{H}, J=8 \mathrm{~Hz}), 10.69(\mathrm{~s}, \mathrm{bs}, 2 \mathrm{H})$; $\left.{ }^{13} \mathrm{CNMR} \mathrm{CDCl}_{3}, 400 \mathrm{MHz}\right): \delta \mathrm{H}(\mathrm{ppm})=35.74,55.46,105.08,114.10,116.54,117.84,124.30,124.44$, $128.28,131.28,132.59,152.59,157.98,164.94,165.38$.

\section{Results and Discussion}

\subsection{Physical Characterizations}

This section explains the surface morphology, crystallographic nature, and surface elements of HUC by several characterization methods. Field-emission scanning electron microscopy (Nova-FE-SEM 200-FEI) photo-images were used to examine surface morphology and to measure the physical dimensions of the HUC. Using high-resolution transmission electron microscopy (HR-TEM, FEI TECNAI G2 20 STWIN), the grain-size of HUC was confirmed. The X-ray diffraction pattern (XRD) was utilized to observe the crystal structure by using $\mathrm{Cu}-\mathrm{K} \alpha$ radiation (Bruker D8 Discover; $40 \mathrm{kV}$, $30 \mathrm{MA}$ ). The phase was confirmed by Raman spectrum (Renishaw, in via Raman microscope, UK). The laser beam $(\lambda=532 \mathrm{~nm})$ was used in the wavelength region of $4000-400 \mathrm{~cm}^{-1}$. Fourier transform infrared spectroscopy (FTIR) spectra obtained using Nicolet IR 870 system with pure KBr pellets in the region of $4000-200 \mathrm{~cm}^{-1}$ were explored for functionality confirmation. The X-ray photoelectron spectroscopy (XPS) spectra were acquired using a VG Scientific ESCALAB250, standardizing to the carbon peak C1s at $284.6 \mathrm{eV}$ to identify elemental compositions of HUC and their respective oxidation states. To estimate the Brunauer-Emmett-Teller (BET) surface-area and pore-size, a surface area analyzer instrument (ASAP 2020 USA) was used, and powder compound was vacuum degassed for $18 \mathrm{~h}$ at $200^{\circ} \mathrm{C}$ to remove any potential surface-adsorbed gases and contaminants. For the purpose of analysis, liquid nitrogen was utilized to maintain a temperature of $77 \mathrm{~K}$.

\subsection{Surface Morphology Confirmation}

The FE-SEM image of HUC has demonstrated a mixture of inorganic salts and micro-sized carbon particles. The FE-SEM image, as shown in Figure 1a, has clearly exhibited a smooth surface with about $10 \mu \mathrm{m}$ crystal size, which evidently offers an idea of a porous structure created by organic contents present in the urine sample. In general, the ultimate material yield ( $3-5 \mathrm{gm})$ depends on the heteroatom as well as quantity $(500 \mathrm{~mL})$ of the urine and carbonization temperature. Furthermore, the HR-TEM image of the as-synthesized HUC catalyst has demonstrated the purely crystalline nature with 20-50 nm irregular particle sizes over the scanned area (Figure 1b). The SEAD (Selected area 
electron diffraction) pattern (Figure $1 \mathrm{~b}$ inset image) has revealed a regular sharp spot, which was in agreement with the nanocrystalline nature of the as-prepared HUC catalyst.
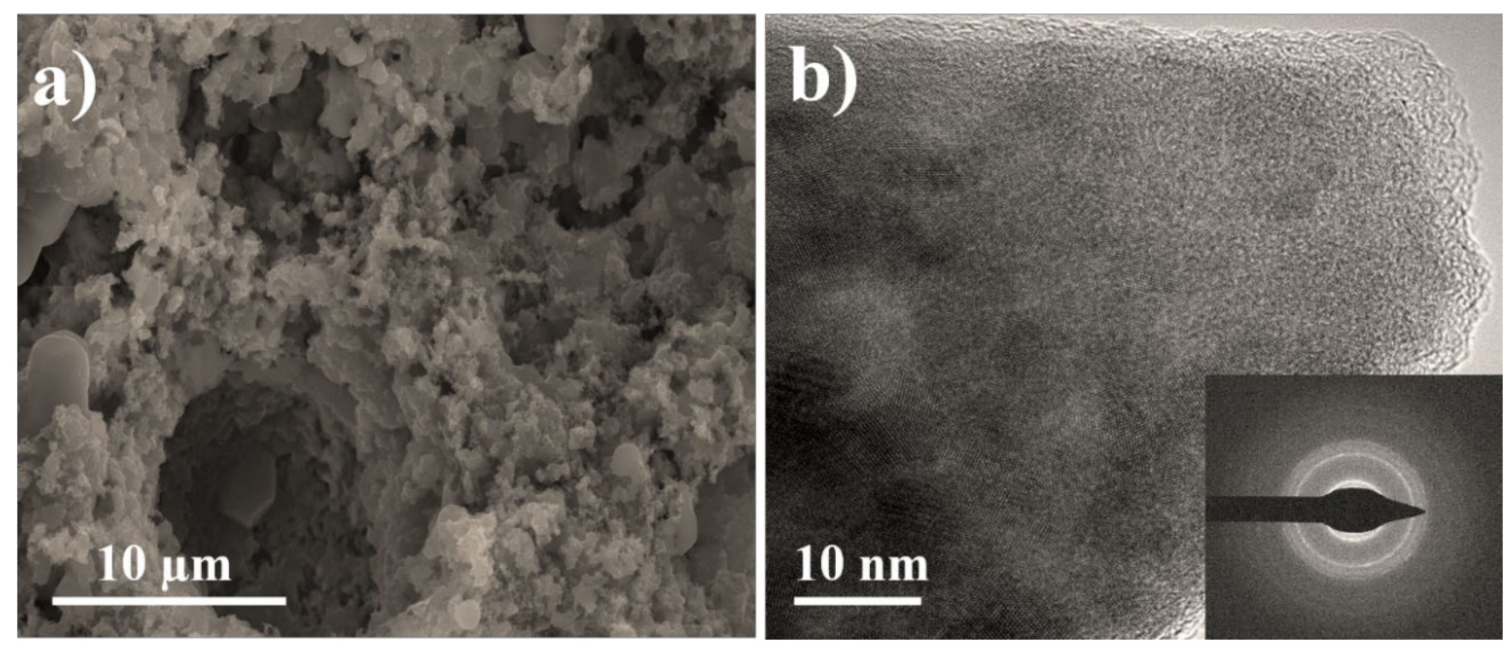

Figure 1. (a) FE-SEM and (b) HR-TEM (inset as SEAD pattern) images of HUC.

\subsection{Structural Elucidation}

The structure evaluation of as-synthesized, i.e., HUC catalyst, was confirmed using XRD. As shown in Figure 2a, the as-prepared product before washing treatment has showed a mixture of carbon and rock salts, which is in good agreement with JCPDS-00-001-0790 (sylvite: $\mathrm{KCl}$ ) and JCPDS-01-072-1688 (halite: $\mathrm{NaCl}$ ). There were also some extra impurity peaks, which are shown with a (•) symbol [23]. The high intensity of XRD peaks could be due to the present of rock salt, and there were two typical peaks at about 24.3 and $44.4^{\circ}$, which can be assigned to (002) and (100) planes of carbon. These were not observed more clearly, but were attributed to the graphitic phase of carbon, which was imperceptible for the samples obtained at lower carbonization temperatures $\left(\leq 300^{\circ} \mathrm{C}\right)$. The more pronounce peak at $44.4^{\circ}$ has exhibited the higher degree of interlayer condensation of graphite, wherein the rock salt and heteroatoms were incorporated/located into the graphite layer of carbon [24]. Furthermore, the present of heteroatom-doped carbon, i.e., $\mathrm{Na}, \mathrm{Cl}, \mathrm{N}, \mathrm{S}$, and $\mathrm{P}$, within the carbon matrix were helped to enhance surface defects and disorders, which in fact are good for obtaining catalytic results [25,26].

The presence of the heteroatoms in the HUC catalyst, as well as phase/structure change, were analyzed by Raman spectroscopy measurement. As a result, the obtained Raman spectrum was similar to that of carbon material, as the intensity of the $\mathrm{D}$ band (ID) was higher than that of the G band (IG), signifying a good structural arrangement (Figure 2b). A high disorder of carbon materials leads to broadening of both $\mathrm{D}$ and $\mathrm{G}$ bands, with higher relative peak intensity of the $\mathrm{D}$ band being related to the defect of carbon materials (the doping of metal atoms in the carbon matrix) as compared to that of the G-band [27]. The Raman spectrum of the HUC catalyst has showed two well-distinguished peaks, at $1344 \mathrm{~cm}^{-1}$ and $1559 \mathrm{~cm}^{-1}$, which normally imply the presence of a zone-edge $\mathrm{A}_{1 \mathrm{~g}}$ mode of defect or disorder in a graphitic structure (D band) and a $E_{2 g}$ mode of graphite (G-band), with an ID/IG intensity ratio equal to 98.65 , showing the low degree of graphitization and a predominant carbon structure, respectively [28]. FT-IR analysis also demonstrates the structure of carbon by the characteristic peaks, i.e., $3418 \mathrm{~cm}^{-1}$ located at $s p^{2}$ carbon functionalized through graphite hydroxyl $(-\mathrm{OH}), 2924 \mathrm{~cm}^{-1}$ for $\mathrm{C}-\mathrm{H}$ stretching in alkane or aromatic compounds, $1634 \mathrm{~cm}^{-1}$ for $\mathrm{C}=\mathrm{C}$ aromatic stretching molecules, $1530 \mathrm{~cm}^{-1}$ for $\mathrm{C}=\mathrm{N}, 1118 \mathrm{~cm}^{-1}$ for $\mathrm{C}=\mathrm{O} / \mathrm{C}-\mathrm{O}-\mathrm{C}$, and $1026 \mathrm{~cm}^{-1}$ for the silica-containing mineral $\mathrm{Si}-\mathrm{O}$ stretching vibrations of back bone carbon (Figure 2c) $[29,30]$. 

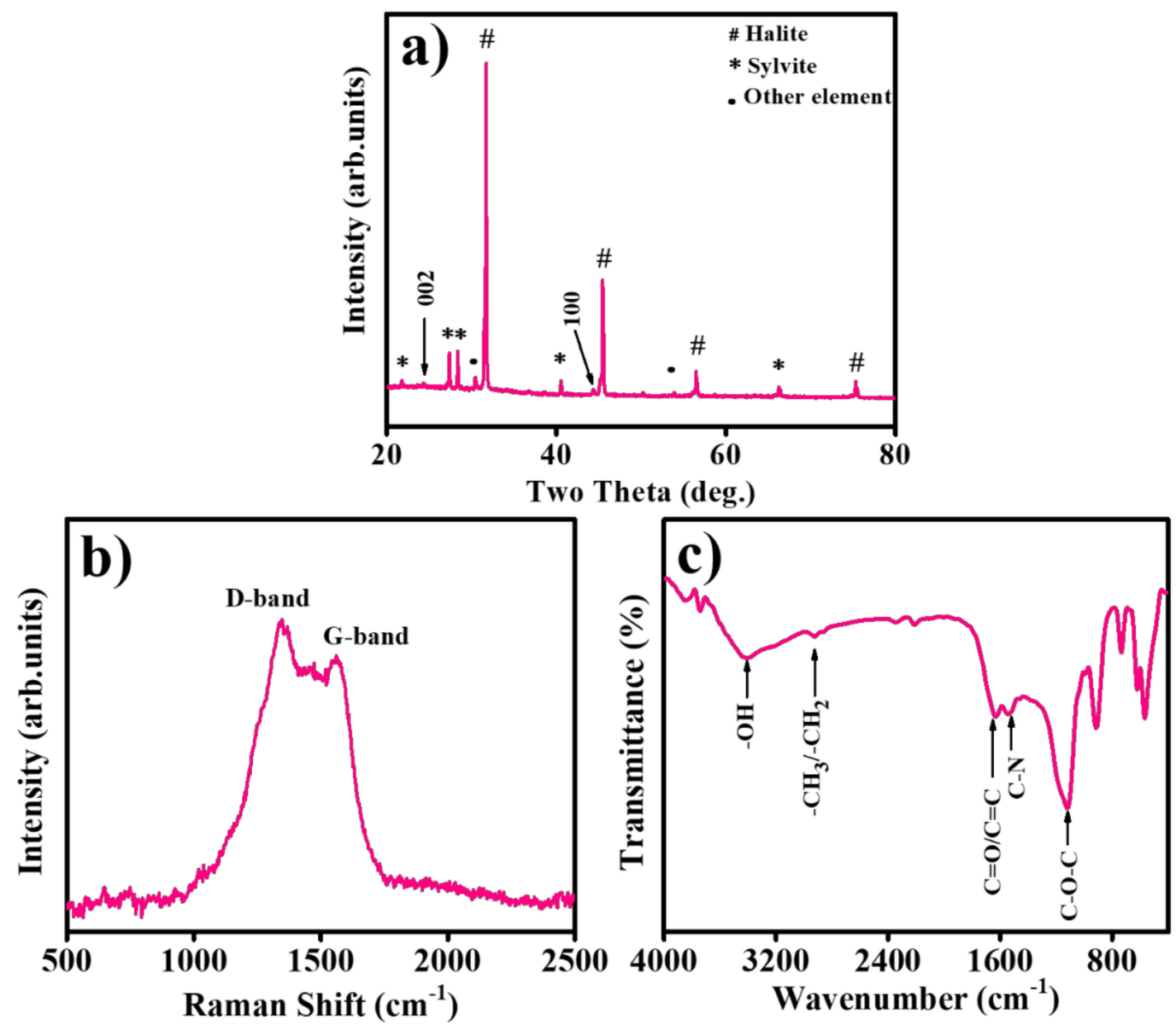

Figure 2. (a) XRD, (b) Raman analysis, and (c) FTIR patterns of HUC.

\subsection{Surface Elements}

The surface chemical compositions and oxidation states of elements were determined using the XPS survey spectrum, as shown in Figure S1, supporting the presence of the $\mathrm{C}, \mathrm{Na}, \mathrm{Cl}, \mathrm{P}$, and $\mathrm{N}$ as major elements of HUC, and K, S, and Si as minor elements (Table S1). It was experimentally accepted that a heteroatom can introduce defects into the carbon backbone that facilitates ion transport rate, which significantly increases the catalyst reaction rate/activity [31]. The incorporation of heteroatoms into porous carbon may increase electrical conductivity, influence surface wettability, inducing a negative charge on the carbon surface and enhancing the electro-active surface area [32]. Furthermore, heteroatom-doped carbons at various active sites play significant roles in catalytic activity because of their freely available lone pairs of electrons for the interactions with oxygen [33]. Figure 3a-f shows the de-convoluted C1s, Cl2p, Na1s, N1s, P2p, and S2p photoelectron envelopes of the HUC catalyst, implying heteroatoms can be doped onto the carbon boundaries and deficiencies at lower temperatures, which increases the catalytic action of carbonaceous materials. As shown in Figure 3a, the C1s peak was deconvoluted into three major peaks of carbon at $284.3 \mathrm{eV}$ and can be exhibited to the aromatic or $s p^{2}$ (-C-C-) bond. The peak at $285.7 \mathrm{eV}$ corresponded to carbon atoms bound to $\mathrm{N}$ and $\mathrm{S}$ in the form of thiols or sulfonates. The smaller and broader peak around $288.7 \mathrm{eV}$ corresponded to carbonyl or amino groups [34]. The extreme resolution Na1s peak showed a major peak at $1071.6 \mathrm{eV}$ for HUC samples (Figure 3b). The high-resolution scan of the N1s signal has showed two dominant peaks as pyridinic-N1 and pyrrolic- $\mathrm{N}_{2}$ (Figure 3d), which is attributed to the presence of the nitrogen content $(6.8 \%)$ [35]. The S2p spectrum, as shown in Figure 3f, was deconvoluted into two peaks of aliphatic thiols or thioethers $(164.2 \mathrm{eV})$ and aromatic thiophenic sulfur $(168.4 \mathrm{eV})$, respectively [36]. 

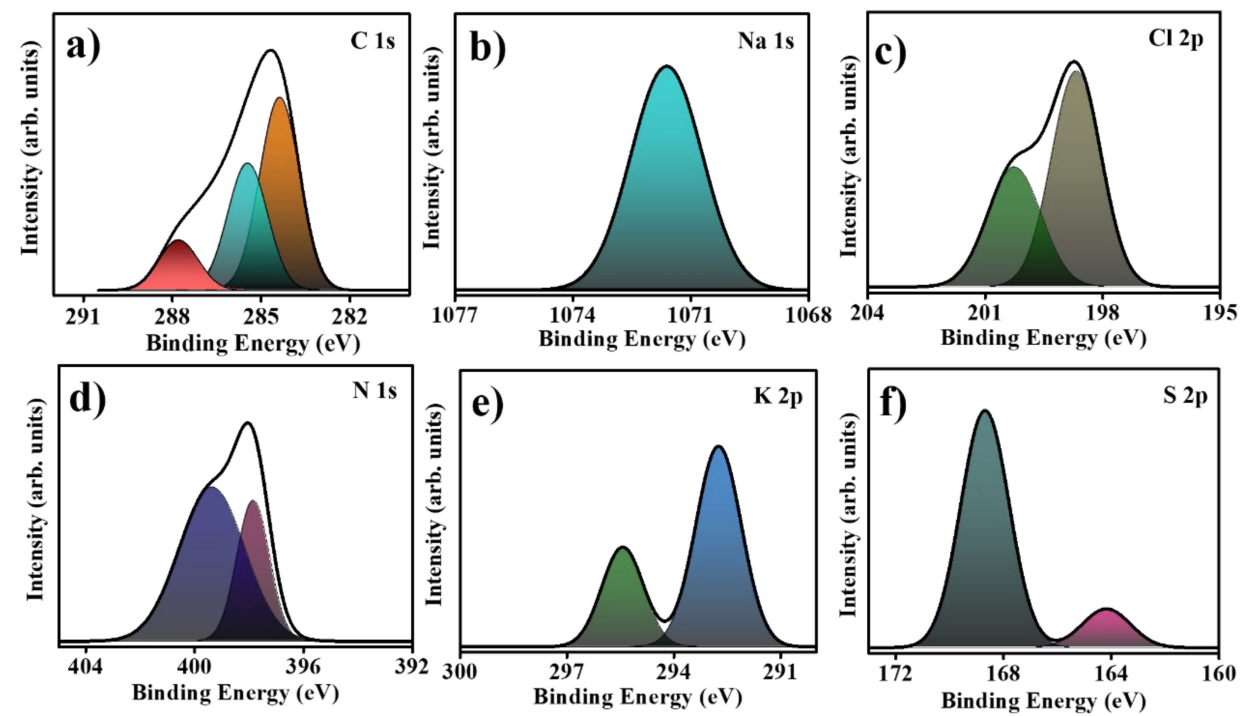

Figure 3. Deconvoluted XPS spectra of (a) C1s, (b) Na1s, (c) Cl2p, (d) N1s, (e) K2p, and (f) S2p for HUC.

\subsection{Surface-Area and Pore-Size Distribution Studies}

The specific surface area was calculated by using the multipoint BET equation. Before investigation, to evacuate the contaminants (water vapors and adsorbed gases), the $\mathrm{HUC}$ was degassing at $200{ }^{\circ} \mathrm{C}$ for $24 \mathrm{~h}$ prior to BET measurement. Subsequent to degassing, the surface area and porosity of the HUC were subjected to a broad range multipoint BET plot in the relative pressure range $\left(P / P_{0}\right)$ of $0.05-0.35$, producing nitrogen adsorption-desorption isotherms [37]. Nitrogen adsorption-desorption isotherms were belonged to the type IV isotherm of the $\mathrm{H}_{3}$ hysteresis loop, i.e., the monolayer-multi-layered adsorption, as revealed in Figure 4a. A very high BET surface area of $1238 \mathrm{~m}^{2} / \mathrm{g}$ was achieved through the multipoint BET equation in the relative pressure, as illustrated in Figure $4 \mathrm{~b}$. The porosity values were calculated by Barrett-Joyner-Halenda (BJH) and Dubinin-Astakhov (DA) methods, which came out to be $45.03 \AA$ and $43.8 \AA$, respectively (Figure $4 \mathrm{c}, \mathrm{d}$ ). The obtained pore-sizes clearly validated the mesoporous nature of HUC [38,39].
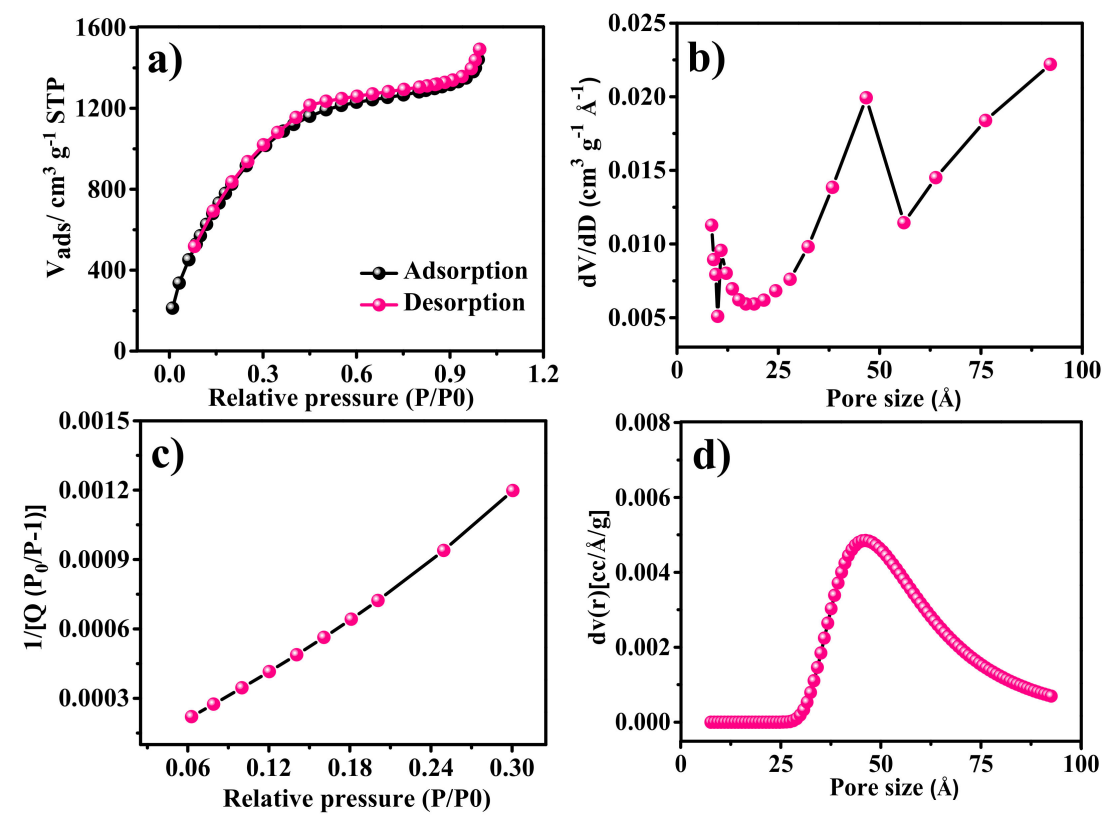

Figure 4. (a,b) Surface area, pore-size distribution, and $(\mathbf{c}, \mathbf{d})$ porosity distribution measurements of HUC. 


\subsection{One-Pot Synthesis of Chromene Derivatives}

Initially, a model reaction was studied with different amounts of HUC catalyst to optimize the reaction condition. The one-pot three component condensation reaction was used to test the catalytic activity of 2-amino-7,7-dimethyl-5-oxo-4-phenyl-5,6,7,8-tetrahydro-4H-chromene-3-carbonitrile derivatives, where we designated the reaction of dimedone (1), substituted aromatic aldehydes (2), and malononitriles (3) as a model three-component condensation reaction at room-temperature $\left(27-35^{\circ} \mathrm{C}\right)$ in $1: 1$ ratio of $\mathrm{EtOH} / \mathrm{H}_{2} \mathrm{O}$ solvent (Scheme 1). The effect of solvents, amount of catalyst, reaction temperature, time, and percent yield on the synthesis of the chromene derivative is provided in Table 1. For the optimization of the reaction condition, the reaction took place at room-temperature in the absence of catalyst, and there was not any progress in the reaction (Table 1 entry 1). However, when the reaction mixture was heated at $100{ }^{\circ} \mathrm{C}$ in the absence of catalyst, only traces of product were noted (Table 1 entry 2). From the above optimization, we concluded that in absence of either catalyst or solvent, the reaction did not take place. When $10 \mathrm{mg}$ of catalyst was loaded under solvent-free conditions at $100{ }^{\circ} \mathrm{C}$, only $70 \%$ of yield was achieved (Table 1 entry 3). When methanol solvent was employed at room temperature, the catalyst provided positive signs towards the effectiveness of the polar protic solvent (Table 1 entry 4 ), offering $85 \%$ of yield. When reaction was checked with increased amount of catalyst $(20 \mathrm{mg})$ for the proposed reaction, there was enhancement of product yield up to 90\% (Table 1 entry 5). The reaction was checked in acetonitrile solvent at room- temperature, where a trace amount of product was formed (Table 1 entry 6). On employing only water as a reaction media, a lesser amount of product formed at room-temperature (Table 1 entry 7), which on heating to reflux temperature, a good amount of yield was obtained (Table 1 entry 8 ). When isopropyl alcohol and dichloromethane were used, no satisfactory amount of yield was obtained (Table 1 entry 9, 10, 11). When toluene, acetic acid, and ethanol were used, moderate yield was obtained (Table 1 entry 12, 13). When $\mathrm{EtOH} / \mathrm{H}_{2} \mathrm{O}$ was employed, the highest yield was noted $(97 \%)$, suggesting the necessity of aqueous media along with ethanol for endowing good results at room- temperature using only $20 \mathrm{mg}$ of catalyst (Table 1, entry 14). Moreover, using a greater amount of catalyst, up to $30 \mathrm{mg}$ of HUC, did not improve the reaction yields (Table 1 entry 15). This could be due to the enervation of the catalytic active site or attainment of maximum conversion efficiency of the catalyst. With the optimized conditions in hand, the synthetic scope of three-component construction of chromene derivatives was then studied. As indicated by the results shown in Table 2, the present method displayed outstanding tolerance to the three components involved. For aldehydes, the presence of both electron donating and withdrawing substituents in the ortho, meta and para positions $(4 \mathrm{a}-4 \mathrm{~m})$ were well tolerated.

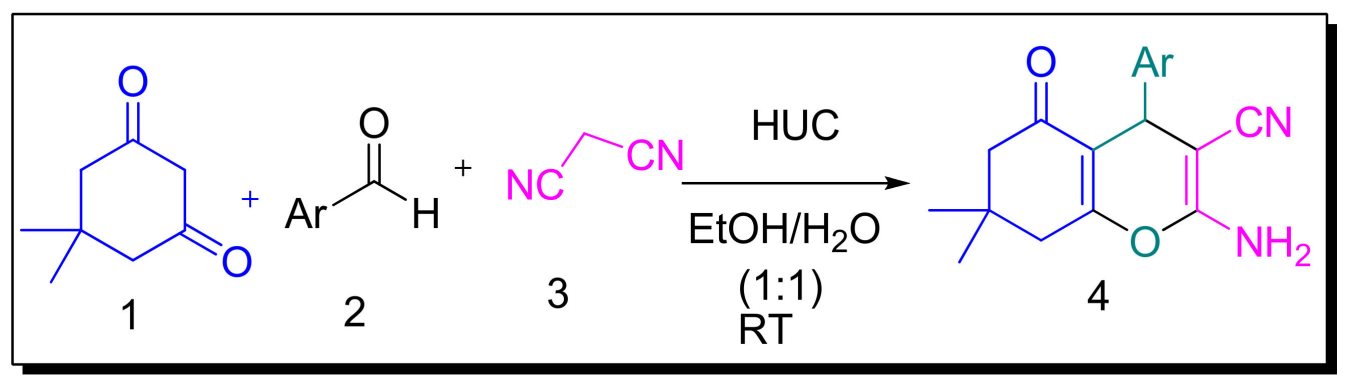

Scheme 1. HUC as catalysts for formation of chromene derivatives. 
Table 1. The optimization of reaction parameters for the synthesis of chromene derivatives ${ }^{\text {a }}$.

\begin{tabular}{|c|c|c|c|c|c|}
\hline Sr. No & Catalyst (mg) & Solvent & Temp. $\left({ }^{\circ} \mathrm{C}\right)$ & Time (h) & Yield (\%) ${ }^{b}$ \\
\hline 1 & - & No solvent & RT & 3 & 0 \\
\hline 2 & - & No solvent & 100 & 3 & Trace \\
\hline 3 & 10 & No solvent & 100 & 1.5 & 70 \\
\hline 4 & 10 & $\mathrm{CH}_{3} \mathrm{OH}$ & RT & 5 & 85 \\
\hline 5 & 20 & $\mathrm{CH}_{3} \mathrm{OH}$ & RT & 5 & 90 \\
\hline 6 & 20 & $\mathrm{CH}_{3} \mathrm{CN}$ & RT & 5 & Trace \\
\hline 7 & 20 & $\mathrm{H}_{2} \mathrm{O}$ & RT & 6 & 40 \\
\hline 8 & 20 & $\mathrm{H}_{2} \mathrm{O}$ & Reflux & 1 & 80 \\
\hline 9 & 20 & IPA & Reflux & 1 & Trace \\
\hline 10 & 20 & $\mathrm{CH}_{2} \mathrm{Cl}_{2}$ & RT & 6 & Trace \\
\hline 11 & 20 & $\mathrm{CH}_{2} \mathrm{Cl}_{2}$ & Reflux & 1.5 & 50 \\
\hline 12 & 20 & Toluene & RT & 3 & 70 \\
\hline 13 & 20 & $\mathrm{EtOH}$ & RT & 5 & 90 \\
\hline 14 & 20 & $\mathrm{H}_{2} \mathrm{O} / \mathrm{EtOH}$ & RT & 4 & 97 \\
\hline 15 & 30 & $\mathrm{H}_{2} \mathrm{O} / \mathrm{EtOH}$ & RT & 4 & 97 \\
\hline
\end{tabular}

a Reaction conditions: dimedone (100 mg), benzaldehyde (1 equivalent), malanonitrile (1 equivalent), HUC (20 mg), and solvent $(2 \mathrm{~mL})$ with constant magnetic stirring at room-temperature. ${ }^{\mathrm{b}}$ Isolated yield; RT-room-temperature.

Table 2. Synthesis of chromene derivatives $4 \mathrm{a}-4 \mathrm{~m}^{\mathrm{a}}$ using HUC catalyst.

\begin{tabular}{ccccc}
\hline Entry & Ar & Product & Time (h) & Yield (\%) $^{\mathbf{b}}$ \\
\hline 1 & $\mathrm{C}_{6} \mathrm{H}_{5}$ & $4 \mathrm{a}$ & 2 & 97 \\
2 & $4-\mathrm{OMe}-\mathrm{C}_{6} \mathrm{H}_{5}$ & $4 \mathrm{~b}$ & 2 & 95 \\
3 & $4-\mathrm{Br}_{6} \mathrm{C}_{6} \mathrm{H}_{5}$ & $4 \mathrm{c}$ & 2.5 & 93 \\
4 & $3,4-\mathrm{Di}-\mathrm{Cl}_{5}-\mathrm{C}_{6} \mathrm{H}_{5}$ & $4 \mathrm{~d}$ & 3 & 85 \\
5 & $4-\mathrm{NO}_{2}-\mathrm{C}_{6} \mathrm{H}_{5}$ & $4 \mathrm{e}$ & 3.5 & 93 \\
6 & $3,4-\mathrm{Di}-\mathrm{OMe}-\mathrm{C}_{6} \mathrm{H}_{5}$ & $4 \mathrm{f}$ & 4 & 90 \\
7 & $3-\mathrm{OMe}-\mathrm{C}_{6} \mathrm{H}_{5}$ & $4 \mathrm{~g}$ & 4 & 92 \\
8 & $3,5-\mathrm{Di}-\mathrm{OMe}-\mathrm{C}_{6} \mathrm{H}_{5}$ & $4 \mathrm{~h}$ & 4 & 93 \\
9 & $3-\mathrm{Br}_{6} \mathrm{C}_{6} \mathrm{H}_{5}$ & $4 \mathrm{i}$ & 3 & 90 \\
10 & $4-\mathrm{F}-\mathrm{C}_{6} \mathrm{H}_{5}$ & $4 \mathrm{j}$ & 5 & 80 \\
11 & $4-\mathrm{Cl}-\mathrm{C}_{6} \mathrm{H}_{5}$ & $4 \mathrm{k}$ & 3 & 95 \\
12 & $4-\mathrm{OH}-\mathrm{C}_{6} \mathrm{H}_{5}$ & $4 \mathrm{l}$ & 3 & 85 \\
13 & $2-\mathrm{Cl}-\mathrm{C}_{6} \mathrm{H}_{5}$ & $4 \mathrm{~m}$ & 4 & 80
\end{tabular}

a Reaction conditions: dimedone (100 mg), benzaldehyde (1 equivalent), malanonitrile (1 equivalent), HUC (20 mg), and $\mathrm{EtOH} / \mathrm{H}_{2} \mathrm{O}$ solvent $(2 \mathrm{~mL})$ with constant magnetic stirring at room temperature. ${ }^{\mathrm{b}}$ Isolated yield.

\subsection{One-Pot Synthesis of 1,8-Di-Oxo-Octahydroxanthene Derivatives}

In the last few years, considerable interest has been attracted by xanthene derivatives mainly in the areas of pharmaceutical and industrial chemistry due to its wide range of pharmacological properties. In addition, it can be useful in many organic compounds, laser technology, dye, and fluorescent materials for the visualization of biomolecules [40]. The outstanding catalytic productivity of the HUC catalyst for synthesis of chromene derivatives has inspired us to discover their capabilities for the synthesis of bioactive highly functionalized 1,8-di-oxo-octahydroxanthene derivative 5 from the reaction of one equivalent of benzaldehyde 2 and dimedone 1 in the presence of HUC catalyst $(20 \mathrm{mg})$ in EtOH/ $\mathrm{H}_{2} \mathrm{O}$ solvent at room-temperature (Scheme 2) Optimization of reaction conditions in different solvents was also studied in details, as shown in Table S2. With the detailed reaction conditions in hand, we further proceeded to the synthesis of various substituted derivatives for the formation of xanthene derivatives, as revealed in Table S3. 


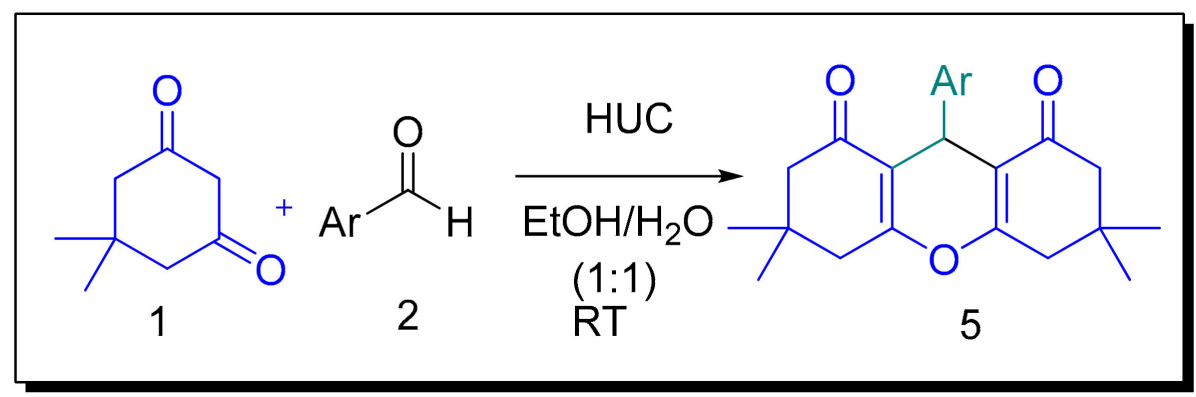

Scheme 2. Use of HUC catalyst for forming xanthene derivatives.

The formation of 1,8-di-oxo-octahydroxanthene derivatives was confirmed by ${ }^{1} \mathrm{H}$ NMR spectroscopy data. The overall reaction mechanism for the synthesis of xanthene derivatives was performed in non-hazardous polar protic solvent $\left(\mathrm{EtOH} / \mathrm{H}_{2} \mathrm{O}\right)$, and finally the products were recrystallized in ethanol solvent. The purification of the compound through time-consuming column chromatography was avoided in this protocol; the detailed mechanism of the reaction is provided in Scheme S2.

\subsection{One-Pot Synthesis of Benzylpyrazolylcoumarin and Bis-Coumarin Derivatives}

To expand the scope of this method and the HUC catalyst product, we also reported the synthesis of benzylpyrazolylcoumarin and bis-coumarin derivatives (Schemes 3 and 4) by the reaction of 4-hydroxycoumarin ( $100 \mathrm{mg}) 8$ with phenyl hydrazine (1 equivalent) 6 , ethyl acetoacetate (1 equivalent) 7 , and aromatic aldehydes ( 1 equivalent) 2 under similar conditions as for xanthenes and chromene derivatives. In this study, the optimized model reaction was extended to substitute different aromatic aldehydes with both electron withdrawing and donating groups (Table 3) with the HUC (20 mg) catalyst in polar protic solvent $\left(\mathrm{EtOH} / \mathrm{H}_{2} \mathrm{O}\right)$ at $50{ }^{\circ} \mathrm{C}$ temperature, demonstrating excellent yields (85-97\%).

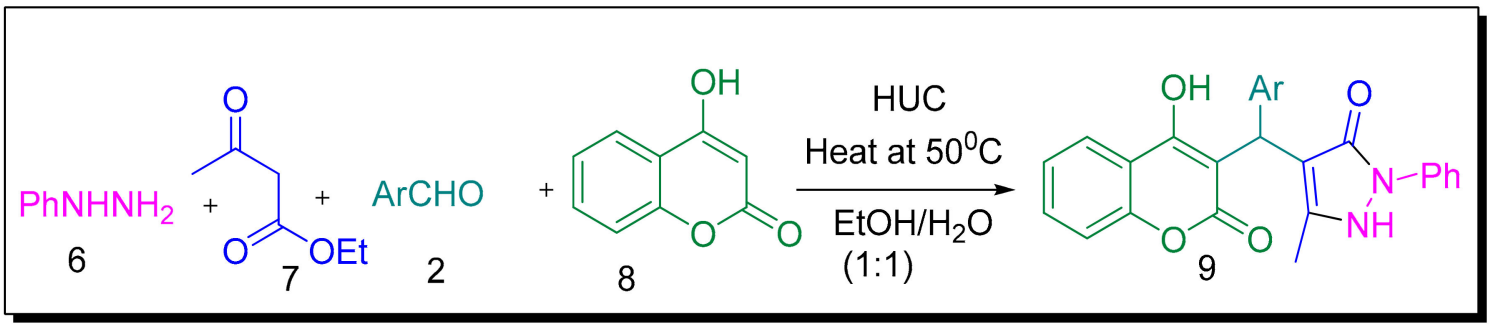

Scheme 3. Use of HUC catalyst for obtaining benzyl pyrazolyl coumarin derivatives.

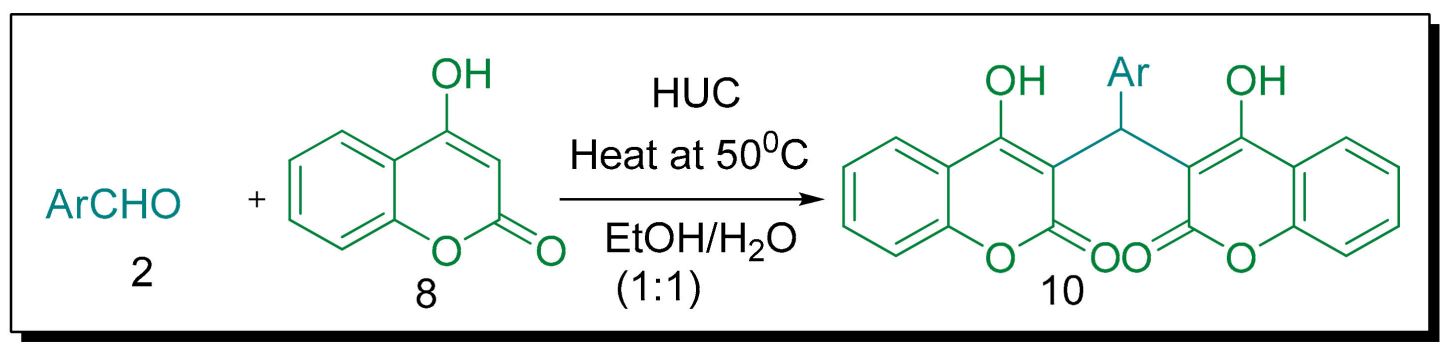

Scheme 4. HUC catalyst for bis-coumarin derivative formation. 
Table 3. Synthesis of benzyl pyrazolyl coumarin derivatives $9 \mathrm{a}-9 \mathrm{~g}{ }^{\mathrm{a}}$ using HUC catalyst.

\begin{tabular}{ccccc}
\hline Entry & Ar & Product & Time (h) & Yield (\%) \\
\hline 1 & $4-\mathrm{NO}_{2}-\mathrm{C}_{6} \mathrm{H}_{5}$ & $9 \mathrm{a}$ & 1 & 97 \\
2 & $4-\mathrm{MeO}-\mathrm{C}_{6} \mathrm{H}_{5}$ & $9 \mathrm{~b}$ & 1.5 & 93 \\
3 & $4-\mathrm{Cl}-\mathrm{C}_{6} \mathrm{H}_{5}$ & $9 \mathrm{c}$ & 1 & 95 \\
4 & $4-\mathrm{Br}_{6} \mathrm{C}_{6} \mathrm{H}_{5}$ & $9 \mathrm{~d}$ & 1 & 95 \\
5 & $3-\mathrm{MeO}-\mathrm{C}_{6} \mathrm{H}_{5}$ & $9 \mathrm{e}$ & 2 & 90 \\
6 & $3-\mathrm{Br}-\mathrm{C}_{6} \mathrm{H}_{5}$ & $9 \mathrm{f}$ & 2.5 & 88 \\
7 & $3,5-\mathrm{Di}-\mathrm{OMe}-\mathrm{C}_{6} \mathrm{H}_{5}$ & $9 \mathrm{~g}$ & 3 & 85 \\
\hline
\end{tabular}

a Reaction conditions: 4-hydroxycoumarin (100 mg), benzaldehyde (1 equivalent), phenyl hydrazine (1 equivalent), ethyl acetoacetate (1 equivalent), $\mathrm{HUC}(20 \mathrm{mg})$, and $\mathrm{EtOH} / \mathrm{H}_{2} \mathrm{O}$ solvent $(2 \mathrm{~mL})$ with continuous stirring at room temperature. ${ }^{\mathrm{b}}$ Isolated yield.

In terms of the suitability of the protocol, the optimized model reaction was extended to different substituted aromatic aldehydes with electron withdrawing and donating groups to generalize the suitability of the protocol (Table 4). The corresponding compounds (10a-e) synthesized by the reaction of 4-hydroxycoumarin (100 mg) and benzaldehyde (1 equivalent) using HUC (20 mg) catalyst in $\mathrm{EtOH} / \mathrm{H}_{2} \mathrm{O}$ solvent at $50{ }^{\circ} \mathrm{C}$ temperature demonstrated excellent yields $(85-97 \%)$. The key advantages of this methodology include broad range of functional groups in starting materials, no need to conduct column chromatography, and the shortest time of reaction. The structure of compounds was confirmed through ${ }^{1} \mathrm{H}$ and ${ }^{13} \mathrm{C}$ NMR spectral data. The respective table shows that in all cases, the reactions proceeded well to afford the corresponding products with excellent yields.

Table 4. Synthesis of bis-coumarin derivatives 10a-10e a using HUC catalyst.

\begin{tabular}{ccccc}
\hline Entry & Ar & Product & Time (h) & Yield (\%) \\
\hline 1 & $4-\mathrm{Me}-\mathrm{C}_{6} \mathrm{H}_{5}$ & $10 \mathrm{a}$ & 1.5 & 97 \\
2 & $4-\mathrm{MeO}-\mathrm{C}_{6} \mathrm{H}_{5}$ & $10 \mathrm{~b}$ & 1 & 95 \\
3 & $4-\mathrm{Cl}-\mathrm{C}_{6} \mathrm{H}_{5}$ & $10 \mathrm{c}$ & 1 & 96 \\
4 & $3,4-\mathrm{DI}-\mathrm{OMe}-\mathrm{C}_{6} \mathrm{H}_{5}$ & $10 \mathrm{~d}$ & 2 & 90 \\
5 & $3-\mathrm{OMe}-\mathrm{C}_{6} \mathrm{H}_{5}$ & $10 \mathrm{e}$ & 2.5 & 85 \\
\hline
\end{tabular}

a Reaction conditions: 4-hydroxycoumarin (100 mg), benzaldehyde (1 equivalent), $\mathrm{HUC}(20 \mathrm{mg})$, and $\mathrm{EtOH} / \mathrm{H}_{2} \mathrm{O}$ solvent $(2 \mathrm{~mL})$ with continuous stirring at room temperature. ${ }^{\mathrm{b}}$ Isolated yield.

\subsection{HUC Catalyst Reusability}

After completion of the model reaction, the catalyst was simply recovered by diluting the reaction mixture with dichloromethane via the filtration method and subsequently reutilized for a minimum of ten times without significant loss in its catalytic activity. The reusability study revealed a high stability and turnover of HUC catalyst under the employed working conditions (Table 5). The extraordinary product yield, the fashioning of an efficient reusable catalyst, and the heterogeneous nature of the technologically advanced methodology are worthy of note. The reusability study of the HUC catalyst in producing various derivatives is novel, economic, chemically stable, and mechanically robust for commercial applications. 
Table 5. Reusability study for synthesis of chromene derivatives ${ }^{a}$ using HUC catalyst.

\begin{tabular}{ccc}
\hline Entry & Time (h) & Yield (\%) $^{\mathbf{b}}$ \\
\hline 1 & 2 & 97 \\
2 & 2 & 97 \\
3 & 2 & 97 \\
4 & 2 & 96 \\
5 & 2 & 96 \\
6 & 2 & 95 \\
7 & 2 & 95 \\
8 & 2 & 94 \\
9 & 2.30 & 93 \\
10 & 2.50 & 92 \\
\hline
\end{tabular}

a Reaction conditions: dimedone (100 mg), benzaldehyde (1 equivalent), malanonitrile (1 equivalent), HUC (20 mg), and $\mathrm{EtOH} / \mathrm{H}_{2} \mathrm{O}$ solvent $(2 \mathrm{~mL})$ with constant magnetic stirring at room temperature. ${ }^{\mathrm{b}}$ Isolated yield.

\section{Conclusions}

In summary, a simple, cost-competitive, and environmentally-friendly method for the synthesis of medicinally important pharmaceutical compounds, i.e., chromenes, 1,8-di-oxo-octahydroxanthenes, and benzypyrazolylcoumarin and biscoumarin derivatives is explored for the first time. The protocols are significantly eco-friendly and sustainable because they utilize a biogenic HUC robust catalyst to deliver the product at room-temperature through a simple procedure. The catalyst can be readily recovered and used effectively for nearly ten times with a marginal decrease in yield, demonstrating chemical stability of the catalyst. A probable model reaction mechanism has also been presented. The HUC catalyst acts as a potential candidate due to its simplicity, lack of need for chromatography, eco-friendly nature, and high percent product yield for large scale applications by replacing existing expensive metal catalysts.

Supplementary Materials: The following are available online at http://www.mdpi.com/2073-4344/10/12/1369/s1, Figure S1: XPS binding energy survey spectrum of HUC, Figure S2: ${ }^{1} \mathrm{H}$ and ${ }^{13} \mathrm{C}$ of 2-amino-4-(4-methoxyphenyl)-7,7dimethyl-5-oxo-5,6,7,8-tetrahydro-4H-chromene-3-carbonitrile (4b), Figure S3: ${ }^{1} \mathrm{H}$ and ${ }^{13} \mathrm{C}$ of 2-amino-4(4-bromophenyl)-7,7-dimethyl-5-oxo-5,6,7,8-tetrahydro-4H-chromene-3-carbonitrile (4C), Figure S4: ${ }^{1} \mathrm{H}$ and ${ }^{13} \mathrm{C}$ of 2-amino-4-(3,4-dichlorophenyl)-7,7-dimethyl-5-oxo-5,6,7,8-tetrahydro-4H-chromene-3-carbonitrile(4d), Figure S5: ${ }^{1} \mathrm{H}$ and ${ }^{13} \mathrm{C}$ of 2-amino-7,7-dimethyl-4-(4-nitrophenyl)-5-oxo-5,6,7,8-tetrahydro-4H-chromene-3-carbonitrile (4e), Figure S6: ${ }^{1} \mathrm{H}$ and ${ }^{13} \mathrm{C}$ NMR of 2-amino-4-(3,4-dimethoxyphenyl)-7,7-dimethyl-5-oxo-5,6,7,8-tetrahydro-4Hchromene-3-carbonitrile(4f), Figure $57:{ }^{1} \mathrm{H}$ and ${ }^{13} \mathrm{C}$ of 2-amino-4-(3-methoxyphenyl)-7,7-dimethyl-5-oxo-5,6,7,8tetrahydro-4H-chromene-3-carbonitrile(4g), Figure S8: ${ }^{1} \mathrm{H}$ and ${ }^{13} \mathrm{C}$ of 2-amino-4-(3,5-dimethoxyphenyl)-7,7dimethyl-5-oxo-5,6,7,8-tetrahydro-4H-chromene-3-carbonitrile (4h), Figure S9: ${ }^{1} \mathrm{H}$ and ${ }^{13} \mathrm{C}$ of 2-amino-4-(3bromophenyl)-7,7-dimethyl-5-oxo-5,6,7,8-tetrahydro-4H-chromene-3-carbonitrile (4i), Figure S10: ${ }^{1} \mathrm{H}$ and ${ }^{13} \mathrm{C}$ of 2-amino-4-(4-fluorophenyl)-7,7-dimethyl-5-oxo-5,6,7,8-tetrahydro-4H-chromene-3-carbonitrile 4j, Figure S11: ${ }^{1} \mathrm{H}$ and ${ }^{13} \mathrm{C}$ NMR of 2-amino-4-(4-chlorophenyl)-7,7-dimethyl-5-oxo-5,6,7,8-tetrahydro-4H-chromene-3-carbonitrile (4k), Figure S12: ${ }^{1} \mathrm{H}$ and ${ }^{13} \mathrm{C}$ NMR of 2-amino-4-(4-hydroxyphenyl)-7,7-dimethyl-5-oxo-5,6,7,8-tetrahydro-4Hchromene-3-carbonitrile(41), Figure S13: ${ }^{1} \mathrm{H}$ and ${ }^{13} \mathrm{C}$ NMR of 2-amino-4-(2-chlorophenyl)-7,7-dimethyl-5-oxo-5,6,7,8tetrahydro-4H-chromene-3-carbonitrile (4m), Figure S14: ${ }^{1} \mathrm{H}$ NMR of 3,3,6,6-tetramethyl-9-p-tolyl-3,4,5,6,7,9hexahydro-1H-xanthene-1,8(2H)-dione (5a), Figure S15: ${ }^{1} \mathrm{H}$ NMR of 3,3,6,6-tetramethyl-9-(2,3,4-trimethoxyphenyl)3,4,5,6,7,9-hexahydro-1H-xanthene-1,8(2H)-dione(5b), Figure S16: ${ }^{1} \mathrm{H}$ NMR of 3,3,6,6-tetramethyl-9-(4-nitrophenyl)3,4,5,6,7,9-hexahydro-1H-xanthene-1,8(2H)-dione (5c), Figure S17: ${ }^{1} \mathrm{H}$ NMR of 9-(2-chlorophenyl)-3,3,6,6tetramethyl-3,4,5,6,7,9-hexahydro-1H-xanthene-1,8(2H)-dione (5d), Figure S18: ${ }^{1} \mathrm{H}$ NMR of 9-(4-bromophenyl)3,3,6,6-tetramethyl-3,4,5,6,7,9-hexahydro-1H-xanthene-1,8(2H)-dione (5e), Figure S19: ${ }^{1} \mathrm{H}$ NMR of (E)-3,3,6,6tetramethyl-9-(2-nitrostyryl)-3,4,5,6,7,9-hexahydro-1H-xanthene-1,8(2H)-dione (5f), Figure S20: ${ }^{1} \mathrm{H}$ NMR of 9-(2,4-dichlorophenyl)-3,3,6,6-tetramethyl-3,4,5,6,7,9-hexahydro-1H-xanthene-1,8(2H)-dione (5g), Figure S21: ${ }^{1} \mathrm{H}$ NMR of 3,3,6,6-tetramethyl-9-(3,4,5-trimethoxyphenyl)-3,4,5,6,7,9-hexahydro-1H-xanthene-1,8(2H)-dione (5h), Figure S22: ${ }^{1} \mathrm{H}$ NMR of 9-(4-chlorophenyl)-3,3,6,6-tetramethyl-3,4,5,6,7,9-hexahydro-1H-xanthene-1,8(2H)-dione (5i), Figure S23: ${ }^{1} \mathrm{H}$ NMR of 9-(3,4-dimethoxyphenyl)-3,3,6,6-tetramethyl-3,4,5,6,7,9-hexahydro-1H-xanthene1,8(2H)-dione (5j), Figure S24: ${ }^{1} \mathrm{H}$ NMR of 4-((4-hydroxy-2-oxo-2H-chromen-3-yl)(4-nitrophenyl)methyl)-5-methyl2-phenyl-1H-pyrazol-3(2H)-one (9a), Figure S25: ${ }^{13} \mathrm{CNMR}$ of 4-((4-hydroxy-2-oxo-2H-chromen-3-yl)(4-nitrophenyl) methyl)-5-methyl-2-phenyl-1H-pyrazol-3(2H)-one (9a), Figure $326:{ }^{1} \mathrm{HNMR}$ of 3,3'-(p-tolylmethylene)bis (4-hydroxy- 
2H-chromen-2-one) (10a), Figure S27: ${ }^{13} \mathrm{C}$ NMR of 3,3'-(p-tolylmethylene) bis(4-hydroxy-2H-chromen-2-one) (10a), Table S1: Element composition obtained from the XPS analysis for UC materials, Table S2. Optimization of the reaction conditions for the synthesis of Xanthene ${ }^{\mathrm{a}}$, Table S3. synthesis of 1,8-di-oxo-octahydroxanthenes derivatives using HUC as a catalyst, Scheme S1: Mechanism for HUC catalysed synthesis of chromene derivatives, Scheme S2: Mechanism for HUC catalysed synthesis of Xanthene derivatives.

Author Contributions: Conceptualization, S.F.S.; Data curation, T.A.J.S., S.F.S. and R.S.M.; Formal analysis, T.A.J.S., S.D.R., B.B.T., and M.S.S.; Funding acquisition, A.M.A.-E., S.F.S.; Investigation, T.A.J.S.; Methodology, T.A.J.S. and R.S.M.; Project administration, A.M.A.-E., S.F.S. and R.S.M.; Resources, S.F.S. and B.M.T.; Software, S.S.S. and M.U. Supervision, S.F.S. and R.S.M. All authors have read and agreed to the published version of the manuscript.

Funding: This research was funded by Deputyship for Research and Innovation, Ministry of Education in Saudi Arabia through IFKSURG-1435-010.

Acknowledgments: The authors extend their appreciation to the Deputyship for Research and Innovation, "Ministry of Education" in Saudi Arabia for funding this research work through the project number IFKSURG-1435-010.

Conflicts of Interest: The authors declare no conflict of interest.

\section{References}

1. Schnorr, J.M.; Swager, T.M. Emerging Applications of Carbon Nanotubes. Chem. Mater. 2011, $23,646-657$. [CrossRef]

2. Dreyer, D.R.; Jia, H.-P.; Bielawski, C.W. Graphene Oxide: A Convenient Carbocatalyst for Facilitating Oxidation and Hydration Reactions. Angew. Chem. Int. Ed. 2010, 49, 6813-6816. [CrossRef]

3. Su, C.; Loh, K.P. Carbocatalysts: Graphene Oxide and Its Derivatives. ACC Chem. Res. 2013, 46, $2275-2285$. [CrossRef]

4. Navalon, S.; Dhakshinamoorthy, A.; Alvaro, M.; Garcia, H. Carbocatalysis by Graphene-Based Materials. Chem. Rev. 2014, 114, 6179-6212. [CrossRef]

5. Bahuguna, A.; Kumar, A.; Krishnan, V. Carbon-Support-Based Heterogeneous Nanocatalysts: Synthesis and Applications in Organic Reactions. Asian J. Org. Chem. 2019, 8, 1263-1305. [CrossRef]

6. Veerakumar, P.; Thanasekaran, P.; Subburaj, T.; Lin, K.-C. A Metal-Free Carbon-Based Catalyst: An Overview and Directions for Future Research. C J. Carbon Res. 2018, 4, 54. [CrossRef]

7. Testa, C.; Zammataro, A.; Pappalardo, A.; Trusso Sfrazzetto, G. Catalysis with carbon nanoparticles. RSC Adv. 2019, 9, 27659-27664. [CrossRef]

8. Long, J.; Xie, X.; Xu, J.; Gu, Q.; Chen, L.; Wang, X. Nitrogen-Doped Graphene Nanosheets as Metal-Free Catalysts for Aerobic Selective Oxidation of Benzylic Alcohols. ACS Catal. 2012, 2, 622-631. [CrossRef]

9. Gao, Y.; Hu, G.; Zhong, J.; Shi, Z.; Zhu, Y.; Su, D.S.; Wang, J.; Bao, X.; Ma, D. Nitrogen-Doped sp2-Hybridized Carbon as a Superior Catalyst for Selective Oxidation. Angew. Chem. Int. Ed. 2013, 52, 2109-2113. [CrossRef]

10. Yang, H.; Cui, X.; Dai, X.; Deng, Y.; Shi, F. Carbon-catalysed reductive hydrogen atom transfer reactions. Nat. Commun. 2015, 6, 6478. [CrossRef]

11. Yamamoto, S.; Kinoshita, H.; Hashimoto, H.; Nishina, Y. Facile preparation of Pd nanoparticles supported on single-layer graphene oxide and application for the Suzuki-Miyaura cross-coupling reaction. Nanoscale 2014, 6, 6501-6505. [CrossRef]

12. Primo, A.; Neatu, F.; Florea, M.; Parvulescu, V.; Garcia, H. Graphenes in the absence of metals as carbocatalysts for selective acetylene hydrogenation and alkene hydrogenation. Nat. Commun. 2014, 5, 5291. [CrossRef]

13. Su, C.; Tandiana, R.; Balapanuru, J.; Tang, W.; Pareek, K.; Nai, C.T.; Hayashi, T.; Loh, K.P. Tandem Catalysis of Amines Using Porous Graphene Oxide. J. Am. Chem. Soc. 2015, 137, 685-690. [CrossRef]

14. Su, C.; Acik, M.; Takai, K.; Lu, J.; Hao, S.J.; Zheng, Y.; Wu, P.; Bao, Q.; Enoki, T.; Chabal, Y.J.; et al. Probing the catalytic activity of porous graphene oxide and the origin of this behaviour. Nat. Commun. 2012, 3, 1298. [CrossRef]

15. Lerf, A.; He, H.; Forster, M.; Klinowski, J. Structure of Graphite Oxide Revisited. J. Phys. Chem. B 1998, 102, 4477-4482. [CrossRef]

16. Nakajima, T.; Matsuo, Y. Formation process and structure of graphite oxide. Carbon N. Y. 1994, 32, 469-475. [CrossRef]

17. Hummers, W.S.; Offeman, R.E. Preparation of Graphitic Oxide. J. Am. Chem. Soc. 1958, 80, 1339. [CrossRef] 
18. Clark, J.H. Solid Acids for Green Chemistry. ACC Chem. Res. 2002, 35, 791-797. [CrossRef]

19. Sheldon, R.A. Green solvents for sustainable organic synthesis: State of the art. Green Chem. 2005, 7, $267-278$. [CrossRef]

20. Siddiqui, T.A.J.; Ghule, B.G.; Shaikh, S.; Shinde, P.V.; Gunturu, K.C.; Zubaidha, P.K.; Yun, J.M.; O'Dwyer, C.; Mane, R.S.; Kim, K.H. Metal-free heterogeneous and mesoporous biogenic graphene-oxide nanoparticle-catalyzed synthesis of bioactive benzylpyrazolyl coumarin derivatives. RSC Adv. 2018, 8 . [CrossRef]

21. Mayank; Kaur Billing, B.; Agnihotri, P.K.; Kaur, N.; Singh, N.; Jang, D.O. Ionic Liquid-Coated Carbon Nanotubes as Efficient Metal-Free Catalysts for the Synthesis of Chromene Derivatives. ACS Sustain. Chem. Eng. 2018, 6, 3714-3722. [CrossRef]

22. González-Rodal, D.; Przepiórski, J.; López Peinado, A.J.; Pérez-Mayoral, E. Basic-carbon nanocatalysts in the efficient synthesis of chromene derivatives. Valorization of both PET residues and mineral sources. Chem. Eng. J. 2020, 382, 122795. [CrossRef]

23. Chaudhari, N.K.; Song, M.Y.; Yu, J.-S. Heteroatom-doped highly porous carbon from human urine. Sci. Rep. 2014, 4, 5221. [CrossRef] [PubMed]

24. Wang, R.; Lu, G.; Zhuang, H.; Yu, J. Synergistic catalytic effect of light rare earth element and other additives on the degree of graphitization and properties of graphite. J. Mater. Sci. 2017, 52, 663-673. [CrossRef]

25. Wohlgemuth, S.-A.; White, R.J.; Willinger, M.-G.; Titirici, M.-M.; Antonietti, M. A one-pot hydrothermal synthesis of sulfur and nitrogen doped carbon aerogels with enhanced electrocatalytic activity in the oxygen reduction reaction. Green Chem. 2012, 14, 1515-1523. [CrossRef]

26. Lu, J.; Bo, X.; Wang, H.; Guo, L. Nitrogen-doped ordered mesoporous carbons synthesized from honey as metal-free catalyst for oxygen reduction reaction. Electrochim. Acta 2013, 108, 10-16. [CrossRef]

27. Ahamad, T.; Naushad, M.; Ruksana; Alhabarah, A.N.; Alshehri, S.M. N/S doped highly porous magnetic carbon aerogel derived from sugarcane bagasse cellulose for the removal of bisphenol-A. Int. J. Biol. Macromol. 2019, 132, 1031-1038. [CrossRef]

28. Amiri, A.; Shanbedi, M.; Ahmadi, G.; Eshghi, H.; Kazi, S.N.; Chew, B.T.; Savari, M.; Zubir, M.N.M. Mass production of highly-porous graphene for high-performance supercapacitors. Sci. Rep. 2016, 6, 32686. [CrossRef]

29. Wu, X.-L.; Wen, T.; Guo, H.-L.; Yang, S.; Wang, X.; Xu, A.-W. Biomass-Derived Sponge-like Carbonaceous Hydrogels and Aerogels for Supercapacitors. ACS Nano 2013, 7, 3589-3597. [CrossRef]

30. Kang, X.; Zhu, H.; Wang, C.; Sun, K.; Yin, J. Biomass derived hierarchically porous and heteroatom-doped carbons for supercapacitors. J. Colloid Interface Sci. 2018, 509, 369-383. [CrossRef]

31. Yang, Y.; Gu, L.; Guo, S.; Shao, S.; Li, Z.; Sun, Y.; Hao, S. N-Doped Mesoporous Carbons: From Synthesis to Applications as Metal-Free Reduction Catalysts and Energy Storage Materials. Front. Chem. 2019, 7, 761. [CrossRef] [PubMed]

32. Dutta, S.; Bhaumik, A.; Wu, K.C.-W. Hierarchically porous carbon derived from polymers and biomass: Effect of interconnected pores on energy applications. Energy Environ. Sci. 2014, 7, 3574-3592. [CrossRef]

33. Xiong, D.; Li, X.; Fan, L.; Bai, Z. Three-Dimensional Heteroatom-Doped Nanocarbon for Metal-Free Oxygen Reduction Electrocatalysis: A Review. Catalysts 2018, 8, 301. [CrossRef]

34. Chaudhari, K.N.; Song, M.Y.; Yu, J.-S. Transforming Hair into Heteroatom-Doped Carbon with High Surface Area. Small 2014, 10, 2625-2636. [CrossRef] [PubMed]

35. Zhao, Q.; Ma, Q.; Pan, F.; Wang, Z.; Yang, B.; Zhang, J.; Zhang, J. Facile synthesis of nitrogen-doped carbon nanosheets as metal-free catalyst with excellent oxygen reduction performance in alkaline and acidic media. J. Solid State Electrochem. 2016, 20, 1469-1479. [CrossRef]

36. Razmjooei, F.; Singh, K.; Kang, T.H.; Chaudhari, N.; Yuan, J.; Yu, J.-S. Urine to highly porous heteroatom-doped carbons for supercapacitor: A value added journey for human waste. Sci. Rep. 2017, 7, 10910. [CrossRef] [PubMed]

37. Al-Enizi, A.M.; Ubaidullah, M.; Ahmed, J.; Ahamad, T.; Ahmad, T.; Shaikh, S.F.; Naushad, M. Synthesis of NiOx@NPC composite for high-performance supercapacitor via waste PET plastic-derived Ni-MOF. Compos. Part B Eng. 2020, 183, 107655. [CrossRef]

38. Al-Enizi, A.M.; Ahmed, J.; Ubaidullah, M.; Shaikh, S.F.; Ahamad, T.; Naushad, M.; Zheng, G. Utilization of waste polyethylene terephthalate bottles to develop metal-organic frameworks for energy applications: A clean and feasible approach. J. Clean. Prod. 2020, 248, 119251. [CrossRef] 
39. Ubaidullah, M.; Ahmed, J.; Ahamad, T.; Shaikh, S.F.; Alshehri, S.M.; Al-Enizi, A.M. Hydrothermal synthesis of novel nickel oxide@nitrogenous mesoporous carbon nanocomposite using costless smoked cigarette filter for high performance supercapacitor. Mater. Lett. 2020, 266, 127492. [CrossRef]

40. Subodh; Mogha, N.K.; Chaudhary, K.; Kumar, G.; Masram, D.T. Fur-Imine-Functionalized Graphene Oxide-Immobilized Copper Oxide Nanoparticle Catalyst for the Synthesis of Xanthene Derivatives. ACS Omega 2018, 3, 16377-16385. [CrossRef]

Publisher's Note: MDPI stays neutral with regard to jurisdictional claims in published maps and institutional affiliations.

(C) 2020 by the authors. Licensee MDPI, Basel, Switzerland. This article is an open access article distributed under the terms and conditions of the Creative Commons Attribution (CC BY) license (http://creativecommons.org/licenses/by/4.0/). 